Vol. 4

Part 3

1971

\title{
The Biology and Behaviour of a Free-Living Population of Black Rats (Rattus rattus)
}

\author{
R. F. EWER \\ Department of Zoology, University of Ghana
}

INTRODUCTION

II HISTORY OF THE STUDY GROUP ..

III

$$
\text { SOCIAL RELATIONS }
$$

Relations within the group

Behaviour towards interlopers .

IV PATTERNS OF BEHAVIOUR

Maintenance activities

Routine social interactions

Courtship and mating

Ambivalent and displacement behaviour

Reproduction, parental care, development of young

Problem solving

DISCUSSION

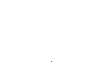

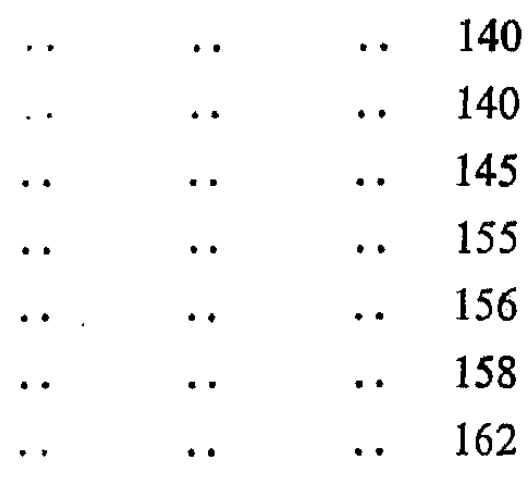




\section{INTRODUCTION}

Although captive Rattus norvegicus have been extensively studied, much less attention has been devoted to Rattus rattus and in neither species is a great deal known about behaviour in the wild. The present study of the latter species was started when, without any design on my part, a favourable opportunity for observing a freeliving population in semi-natural conditions presented itself.

In the neighbourhood of Accra, Rattus rattus is extremely common as a scavenger around human habitations. Indeed, one can virtually say that if food is to be had nearby, then there will be rats in the roofs. The animals studied first made their appearance as raiders on food intended for other animals, but, having decided that they merited detailed observations, I deliberately put out food for the rats every evening at about 17.00 hours (sunset at Accra varies during the year from 17.40 to 18.20 hours GMT).

The majority of the animals were black above and below, the bellies appearing slightly paler only because the hair there is shorter and sparser. Grey individuals with a clearly demarcated white belly appeared now and then and were, of course, easily identified. Breeding in the laboratory from a pair of blacks captured as juveniles in the same area and probably littermates, produced a ratio of ten black : six grey, without intermediates. Two of the grey progeny subsequently mated and produced an all grey litter of eight offspring. Grey would therefore seem to be behaving as a simple recessive and must exist at fairly low frequency in the predominantly black population.

The black colour form agrees well enough with the rattus type, as described by Watson (1950). The grey form comes closest to his frugivorus but differs in that he describes the animals as brown rather than grey. There is, however, a change with age. The juvenile coat is a clear uniform grey, but in an old animal the darker guard hairs produce a colour not unlike that of $R$. norvegicus, which is normally described as 'brown' or agouti. Unfortunately Chasen's (1933) description of the forms of $R$. rattus occurring in the Malay Peninsula is not available to me for comparison.

Worth (1950), working in Florida, found that the rattus animals were distinctly more docile than the frugivorus and Jirsik (1955) found the same thing in Czechoslovakia. Barnett (1958) did not notice any consistent differences in temperament between different colour forms in his animals and neither did I in mine: one grey male was indeed very aggressive but another was particularly timid. The situation, however, may well be different if one is dealing not merely with an occasional light member of a predominantly black population but with distinct populations of the two forms, occupying slightly different habitats.

The Zoology Department, where the work was done, is designed as a series of single storey buildings surrounding a rectangular courtyard, flanked by a continuous covered veranda. Fig. 1 shows the general arrangement of the relevant area. Two feeding places were established at the bases of small trees (actually a species of large shrub, Duranta repens, of spreading form, providing a number of independent routes from the veranda roof to the ground) in the courtyard, one (A) directly outside my laboratory and one (B) at the opposite corner of the courtyard. The rats consistently feeding at $\mathrm{A}$ lived in the roofs at $a_{1}$ and $a_{2}$, while those at $B$ inhabited $b_{1}$ and $b_{2}$. Only cursory observations were made at $\mathbf{B}$, the main attention being devoted to the population at A-the 'home rats'.

Although the roofs were officially rat-proofed, the rats entered them by a number of ways. Trees and creepers offered easy access to the flat roof of the veranda: the principal routes used are shown in Fig. 1. A few branches of the home tree reached across as far as the roof of the building, where the tiles were loose enough to permit the passage of young rats. 


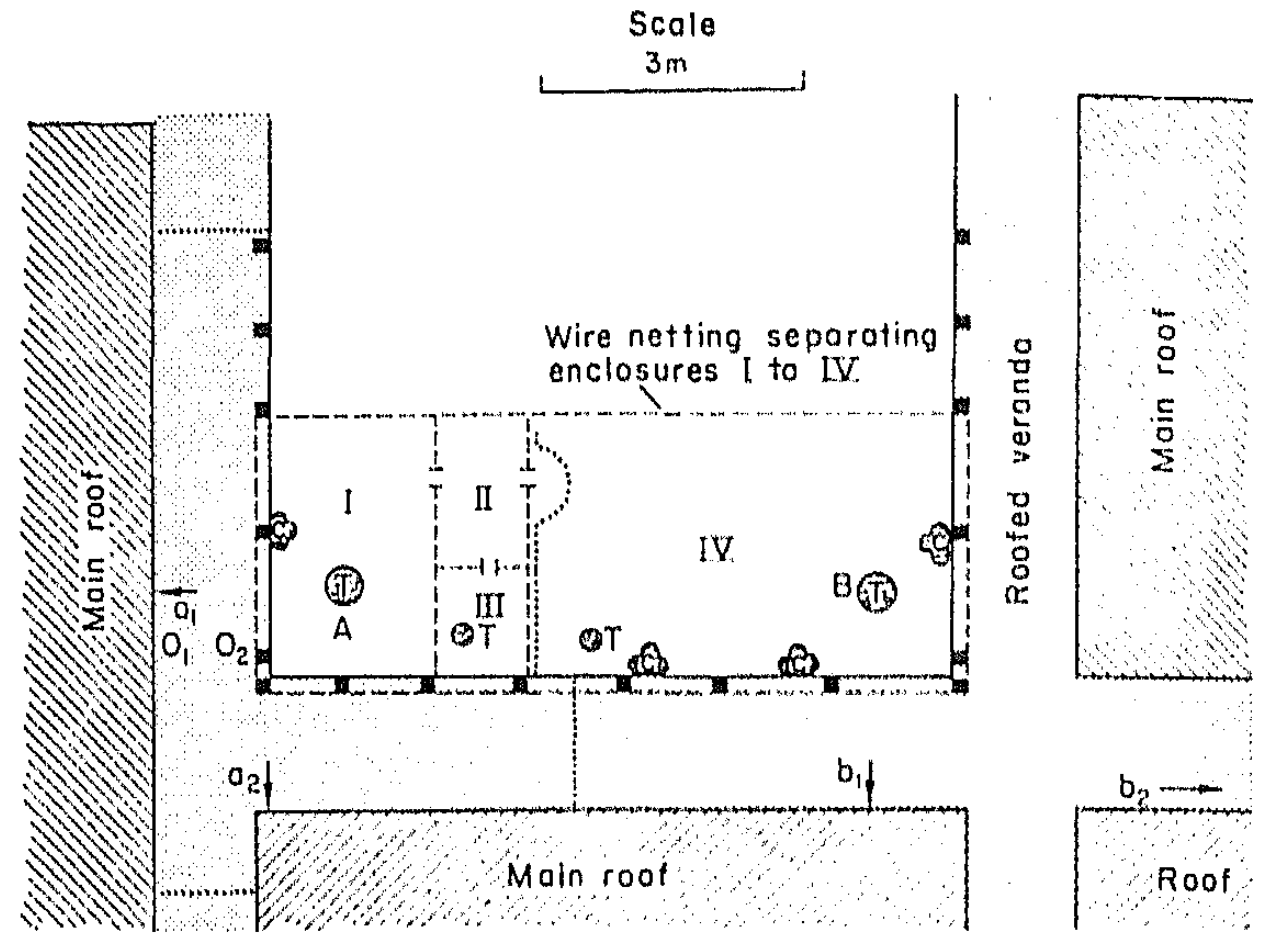

Fig. 1. Plan of courtyard and veranda. A, B, feed places; $a_{1}, a_{2}, b_{1}, b_{2}$, nest areas in roofs; $\mathrm{O}_{1}, \mathrm{O}_{2}$, observation points; trees ( $\mathrm{T}$ ) and creepers (C) give access to roofs of the veranda and main buildings; broken lines, wire netting fencing enclosures I to IV; dotted line, territorial limits of home rats feeding at $\mathrm{A}$.

Larger animals made their way in beneath the eaves through holes in the wire netting (see Fig. 2). Whether they made the holes themselves is not known, but they are capable of

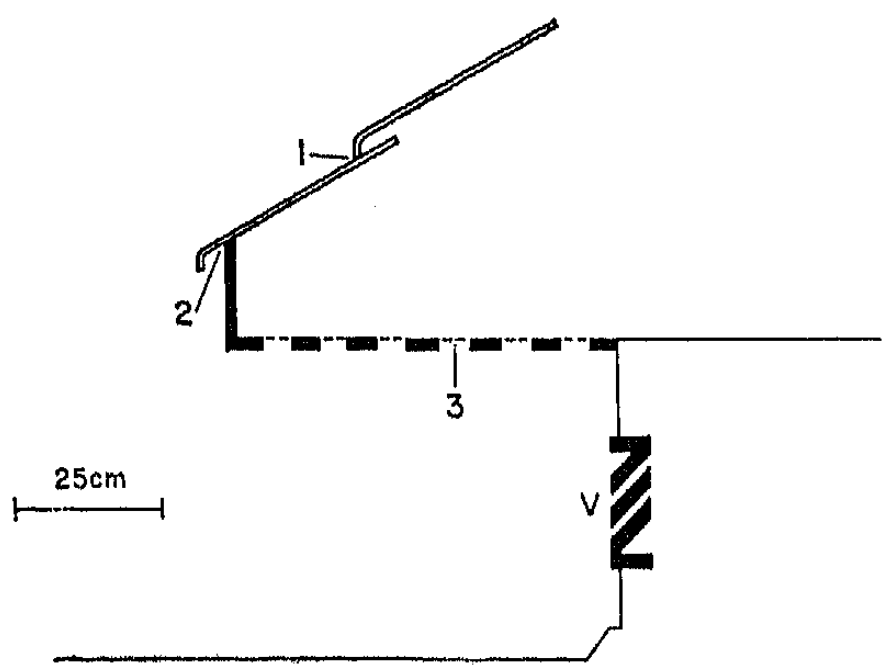

Fig. 2. Sectional view of roof eaves. Parts in solid black are made of wood. $1-3$, rats' points of entry: 1 , between tiles, which do not fit closely across their whole width; 2 , by gnawing a hole in the top of the wooden joist; 3 , through holes in the wire netting forming the lower surface of the overhanging eaves; $V$, louvred ventilator, providing easier access to 3 . doing so, especially if the wire is slightly rusted. The netting was most easily reached by running up the wooden ventilator louvres and jumping from these to the netting. The rats were not however, dependent on holes in the netting. An adult rat could jump from the top of the veranda directly to the roof and cling to a corner of the vertical wooden joist. A hole gnawed in the top of the wood between it and the tiles gave passage for rats too large to pass between the tiles. They were also able to jump a distance of at least half a metre in either direction between tree branches and rooftop.

The courtyard contained a number of interconnected wire netting enclosures, previously used for keeping other species. The netting was about $1 \mathrm{~m}$ high, with a horizontal piece at the top some 15 or $20 \mathrm{~cm}$ in width. These fences, of course, presented no obstacle to the rats, who scaled them with ease and used the horizontal tops as pathways, but they did provide convent ient boundary lines and therefore had an effect in determining the limits of the territory that was established. 
The rats quickly adapted to my presence but they remained exceedingly easily startled by any quick movement. They were therefore watched from behind an observation screen (Fig. 1, $\mathrm{O}_{1}$ ) which concealed the movements made in writing notes, using a stop watch, etc. Observations were started directly the food had been put out and continued until the main activity associated with feeding had died down - generally about $1 \mathrm{hr}$. The animals were watched again later for a shorter period, starting at 20.30 or 21.00 hours, when I returned and put out a small quantity of food and stood near one of the pillars of the veranda (Fig. 1, $\mathrm{O}_{2}$ ) offering ground nuts to any rat bold enough to take them from my hand. The veranda was lit by ordinary electric lights which were left on and provided sufficient light for observation, without seeming to disturb the rats. A light pair of binoculars giving a magnification of $\times 3$ was found extremely useful.

Watching on the veranda roof was not very rewarding and this was done only now and then. No food was to be found there and the main activity seen was merely passing from the roof to one or other of the routes to the ground. The few observations made did, however, serve to show how the rats gained access to the roofs and established the fact that when large pieces of food were carried up the tree, they were taken right in to the nest areas in the roof.

The rats were watched almost every evening from 2 August 1967 to 26 June 1968 and again from 11 September 1968 to 28 June 1969. During my absence in July to September 1968, feeding was continued but the quantity given was much reduced. The population of rats declined and on my return, having increased the food ration, I was able to study a second cycle of population build up.

Some observations were also made on wild caught animals and their progeny, kept in a cage in the laboratory. The cage had a floor area of $2.5 \times 1 \mathrm{~m}$ and was $2.5 \mathrm{~m}$ high: it was furnished with an earth floor and numerous tree branches leading to nest boxes $1.5 \mathrm{~m}$ above ground level. Four hand reared young were also kept until they had reared offspring, in two small cages, $2 \times 0.3 \times 0.3 \mathrm{~m}$ placed one above the other and linked by a passageway.

The rats were not marked. With continued breeding going on this would have entailed repeated trapping, which would have created disturbance and defeated the whole purpose of the investigation. It was, however, possible to recognize a number of individual rats, mainly by various scars and injuries to tails or ears. Fortunately it was usually the rats occupying the most important social positions that were thus distinguishable. Occasional grey individuals appeared and were, of course, easily identified. The remaining animals were merely recorded as belonging to various categories-adult male or female, sub-adults, juveniles and infants (= young aged up to a week or so after first appearance at the feeding places). Adult males could be further categorized according to whether they were 'smooth', 'shaggy' or 'old'. At about 5 months old the guard hairs in the coat become more prominent and the general appearance becomes rougher as the transition from smooth to shaggy takes place. As they grow older, the coat becomes paler and the general colour changes from virtually black to dark brown. In an old male the fading is particularly marked on the flanks, where the colour becomes so light as to be almost ginger.

Before describing the history of the populations studied, it is necessary to say a little about the general behavioural characteristics of Rattus rattus and also to consider briefly what is implied by the term 'colony.'

Black rats are remarkably agile and are extremely good climbers. They are able to run quickly up and down almost vertical branches and could even run along the top of a wire 1.6 $\mathrm{mm}$ in diameter that stretched between two of the pillars supporting the veranda (Plate I, facing $\mathrm{p}$. $140)$. Worth (1950) records them gaining access to the roofs of buildings by running along telephone wires. The long tail is important as a balance organ and can also be wrapped round a 
branch in a semi-prehensile manner. While running on the wire, the tail is constantly swung from side to side in a wide figure of eight. Its importance is attested by the fact that one rat who had lost the posterior third of her tail was handicapped in wire running and would slip now and then, so that she hung suspended below the wire and had to finish her journey sloth-wise. Accidental falls were rare, but it was not uncommon for one rat to knock another off a high branch. If this happened the victim would sometimes succeed in catching hold of a lower branch as it fell and I once saw one wrap its tail round a branch it chanced to contact; this checked the rat's fall for long enough for it to reach out and clutch another branch. A direct fall from as much as $3 \mathrm{~m}$ height produced no injury. On the one occasion when I clearly saw how the rat landed, it turned as it fell and landed on all four paws, like a cat.

Although they are such expert climbers, black rats are also quite at home on the ground and although they do not normally burrow, they are perfectly capable of digging. Despite their smaller size, they are more skilled and persistent gnawers than $R$. norvegicus (Anon 1966) and even $12 \mathrm{~mm}$ mahogany can be perforated. The slivers of wood detached by this process, up to $35 \mathrm{~mm}$ long $\times 4 \mathrm{~mm}$ wide and $1 \mathrm{~mm}$ in thickness, are surprisingly large in relation to the size of the incisors. Ordinary wire netting is not usually perforated but this can happen if the rat persists in its efforts at the same place for long enough.

Rattus rattus is polyphagous. Almost any food eaten by man will be accepted and in addition leaves from some of the shrubs growing in the courtyard were eaten. The food pro. vided consisted mainly of maize grains, previously soaked in salted water, ground nuts, banana and a variety of domestic scraps. The main feeding place was at $\mathrm{A}$ and a smaller quantity of food was placed at B (see Fig. 1). This made it simple to watch the responses of the home rats at $A$ to intruders, since the tendency for raiders to come from B to $A$ was greater than in the reverse direction.

Rats are commonly said to be colonial. Certainly they do form groups and social relations to group members and to outsiders are different. However, in a natural or near natural situation, the formation of a stable closed colony is hardly to be expected. Small rodents are generally opportunistic in their breeding biology. They are adapted to increase rapidly in numbers when conditions are favourable and must decline in adversity. In the absence of any restricting cage walls, it is to be expected that a rich feeding ground will not only provide a breeding focus from which there will be dispersal outwards but also an attraction point for outsiders. In the event, movement both inward and outward did occur and it is clear that the group must be thought of as a dynamic rather than a static entity. Since the term 'colony' has so often been used to refer to caged populations in which such movement is not possible, I have preferred to avoid it and use the term group instead. 


\section{HISTORY OF THE STUDY GROUP}

When observations were begun in August 1967, the population at $\mathrm{A}$ consisted of nine animals: one adult female, one adult male, four subadults and three small juveniles. Breeding clearly must have occurred in July and from August onwards, until the suspension of observations in July 1968, there was never a month during which new young did not appear at the feeding place. Storer \& Davis (1953) found that in San Francisco, Rattus rattus bred the whole year round, without regular seasonal fluctuation.

Table 1. New Infants Appearing at the Feeding Place During 1967 to 1968

\begin{tabular}{lc}
\hline Date & No. of infants \\
\hline 10 August 1967 & 3 \\
September 1967 & (At least 1 litter-details not noted) \\
16 October 1967 & 5 \\
9 November 1967 & 5 \\
27 November 1967 & 3 \\
6 December 1967 & 2 \\
17 December 1967 & 3 \\
30 December 1967 & 4 (2 black, 2 grey) \\
14 January 1968 & 1 \\
23 January 1968 & 2 \\
4 February 1968 & 3 \\
17 February 1968 & 3 \\
26 February 1968 & 3 \\
11 March 1968 & 1 \\
25 March 1968 & 4 \\
10 April 1968 & 1 \\
22 April 1968 & 4 \\
1 May 1968 & 4 \\
8 May 1968 & 3 \\
23 May 1968 & 2 \\
12 June 1968 & 2 \\
Total & 58 young + 1 litter not counted. \\
\hline & \\
\hline
\end{tabular}

The dates at which young first appeared and the numbers seen are given in Table 1 . The numbers, of course, do not give the actual numbers born. They are not even an accurate record of those that survived to make their way to the feeding place but are bound to be an under-estimate. The infants are usually not distinguishable one from another and the counts are the maximum number visible at any one time. That this does give an under-estimate was demonstrated when at one point a count of four visible at the feeding place was recorded but an investigation on the roof disclosed a group of six infants playing on the top of the veranda beneath the overhanging branches of the tree.

With continued breeding, the population visiting the feeding place soon became so large that it was no longer possible to count the rats accurately. From November onwards, the maximum number seen at one time on each evening was therefore recorded. This again will be an under-estimate of the true number, but it should show whether the population is static, increasing or decreasing. Counts made on evenings when there was some unusual disturbance were discarded and the means and the largest single counts for the first five valid counts made in each month from November onward are given in Table 2. It is clear that once the feeding

Table 2. Number of Rats Seen Simultaneously for the First 5 Counts of Each Month

\begin{tabular}{lcc}
\hline \multicolumn{1}{r}{ Month } & Mean & Maximum \\
\hline November 1967 & 19 & 19 \\
December 1967 & 19 & 20 \\
January 1968 & 18 & 20 \\
February 1968 & 20 & 22 \\
March 1968 & 21 & 23 \\
April 1968 & 21 & 25 \\
May 1968 & 25 & 28 \\
June 1968 & 21 & 23 \\
\hline
\end{tabular}


place had been established, the numbers increased rapidly from the original nine and thereafter stabilized or showed only a minor increase. Stabilization was not a reflection of cessation of breeding and could therefore be accounted for only on the basis of continual emigration or of a high death rate. There was no evidence of the latter; the rats did not lose condition, nor were corpses found but there was both direct and indirect evidence of emigration. Firstly, a number of identifiable healthy young adult or sub-adult animals ceased to appear at the feeding place: sometimes this followed on a period of peripheralization (see below) but sometimes the animals that vanished had not been subjected to any obvious harrying. Secondly, the neighbouring buildings, previously not supporting a noticeable rat population, became infested. Emigration of young adults, therefore, appeared to be taking place at a rate which approximately balanced recruitment to the population. That this is the principal dispersal age is also suggested by the fact that during the whole period, although the number of adults present did increase, they were always outnumbered by young animals. The activity of the rats made it extremely difficult to make simultaneous counts of adults and others and the figures obtained (approximately 40 per cent adults) were certainly inaccurate. They did, however, corroborate the subjective impression that adults were in a minority. The counts were made when feeding activity was at its height. Since the infants often put in their first appearance somewhat later, they were under-represented in the counts and the true proportion of adults was probably less than 40 per cent.

When observations were resumed in midSeptember 1968, the starting population consisted of seven rats: two adult females, one young adult male, a sub-adult male, a juvenile and two very small juveniles who must have made their first appearance in early September. When the food supply was increased to its old level, the population increased, as it had done the previous year. The situation was, however, different, since neighbouring buildings now offered fewer opportunities for dispersal and the course of events was not exactly repeated. Breeding at first proceeded normally, with new young making their appearance every month until March 1969. In April and May no young came down from the roof and the only infants seen were one probable stray seen once only, one that came in from $B$ and three which were born in a nest in a drain running under the veranda (see Table 3 ). This was the only time that breeding was noticed in a nest at ground level and its occurrence suggests that in the roof conditions were unfavourable for the rearing of young.

Table 3. New Infants Appearing at the Feeding Place During 1968 to 1969

\begin{tabular}{ll}
\hline Date & No. of infants \\
\hline Early September 1968 & 2 \\
10 October 1968 & 2 \\
Early November 1968 & 5 \\
Late November 1968 & 5 \\
30 November 1968 & 2 \\
12 December 1968 & 4 \\
2 January 1969 & 2 \\
24 January 1969 & 3 \\
9 February 1969 & 1 \\
1 March 1969 & 3 \\
23 March 1969 & 1 \\
6 April 1969 & $(1-$ seen once only, possibly \\
12 May 1969 & $(3-$ born in drain, not roof $)$ \\
23 May 1969 & $(1-$ came in from B) \\
23 June 1969 & 4 \\
Total from home roof & 34 young-12 litters \\
\hline
\end{tabular}

During this period the population underwent two changes. Firstly there was some decrease in the numbers visiting the feeding place, from counts of over twenty at the end of March to 
less than twenty in April, May and June. The age composition also altered and juveniles, instead of predominating, constituted the minority of the population. Cessation of effective breeding in the home population was not due to the females ceasing to come on heat, for sexual behaviour was seen. That normal sized litters were not being carried to full term was, however, suggested by the fact that the two top-ranking females did not become visibly pregnant during April, May or early June. They may have failed to become pregnant, lost litters early in gestation or given birth to small numbers of young but failed to rear them. The simplest interpretation of the findings is that with a shortage of vacant places in which the maturing young could disperse, a predominantly adult population built up, within which conditions for breeding were unfavourable and the population stabilized by some form of restriction of breeding, instead of by emigration. This restriction was not due to starvation. At no time were the rats in poor condition and furthermore, the female who nested in the drain reared a litter successfully. Living, as she did, outside the main nesting area, she was a peripheral member of the group and it was more difficult for her than for the true home females to obtain her share of the food supply. Despite this, she reared a litter, while they did not. 


\section{SOCIAL RELATIONS}

\section{Relations Within the Group}

Even within the group, relations were by no means wholly peaceful or tolerant and the majority of interactions seen were agonistic. Attacks on fellow group members usually followed a definite pattern in time. At the beginning of the feeding period hostilities were infrequent: the main concern was with eating and until it had had some food, even the most aggressive rat seldom attacked others. Once inmmediate hunger had been satsified however, attacks became common and, apart from arboreal fights between juveniles, consisted mainly of chasing other rats away from the feeding place. Females were much more aggressive than males and this was true at all levels of population density. When observations were started in 1967 there was only one adult female and one adult male but out of twenty-six attacks recorded during the first week* she accounted for twenty-three, the male for only one and the sub-adults for two. Similarly during a week towards the end of October 1968, when the population density was considerably higher, out of a total of fifty-one attacks, thirty-seven were made by the two top ranking females as against ten by the three top males and the remaining four by sub-adults.

Attacks are not distributed indiscriminately but in relation to social position, It is, therefore, simplest to begin by summarizing the organization that became apparent from the pattern both of attacks and responses to attacks and of amicable interactions.

The most obvious point to emerge was that there was never a time when a single male could not easily be picked out as the dominant topranking individual. A top male very rarely fought: normally a hostile move on his part was answered by withdrawal or submissive behaviour and if a

\footnotetext{
*Here and elsewhere, when numbers of any particular type of interaction are given they refer to incidents which took place where they could be properly seen and the individuals concerned identified, at least as far as category. They therefore do not represent the full number of incidents that occurred.
}

brief scuffle did take place, he was always the victor. At one stage, investigations on the roof disclosed that the top male was living in roof $a_{1}$, together with the females and juveniles while the two largest other males occupied $a_{2}$. At two other periods the then current top male was also found to be living in the same place with the breeding females but in these latter cases the location of the other adult males was not determined.

There was only one period when three 'old' males were present, showing the characteristic gingery hair on the flanks. These three were individually recognizable and between them there was a strict linear order. No. 3 always gave place to or was defeated by no. 2 and the latter was always subordinate to the top male. No. 3 , in turn was dominant to every other male in the group. Strict linearity could not be traced further but between the younger, still maturing animals ranking was more labile,

Amongst the females no linear order was ever seen and the only times when there was a single dominant female were when numbers were low and only one fully adult female was present. At other times there were two or more high ranking animals, showing mutual tolerance but each prepared to attack any subordinates.

The distribution of the attacks made by the two sexes is different. Amongst the males and the juveniles, there is a very strong tendency to make attacks only on a smaller individual, with one further restriction. Adult males are very tolerant of adult females and seldom attack them, despite their smaller size. This was demonstrated particularly clearly in the behaviour of a top male who had developed the habit of begging from me at the edge of the veranda, where I could drop a nut just beside him. If any other male approached and tried to share the booty, he was at once driven off, with considerable ferocity. A female, however, was either tolerated or at most 'broadsided' (see p. 147) away rather gently. Adult females, on the other hand, will 
attack virtually any other rat, even a larger animal, with two restrictions. Top ranking females very rarely attack either each other or the top male. If the latter is molested at all, the attack is very minor, often a mere intention movement. Attacks in error are sometimes made but are stopped as soon as the mistake is realised. The top male rarely retaliates: usually he merely fends the female off by turning broadside to her and standing his ground firmly. Specific individuals, usually young adults or sub-adults, sometimes are singled out for particularly vicious persecution by a female. Such treatment results in the victim becoming 'peripheralized'. $\mathrm{He}$ retreats away from the main concentration of food, slips in as he sees a chance to snatch a piece of food and carries it to some distance to eat. He may remain thus as a peripheral member of the group, or this may be the prelude to his emigrating. During the week in September 1968 already mentioned, one male ( $\left.\delta^{*} 2\right)$ was the major target of attacks by one of the top females (이) but Bobtail, the other top ranking female, did not single him out so clearly. He was also the major target of attack by $\delta^{x} 1$, the top male (see Table 4). He was forced further and further on the defensive, was seen more and more rarely and finally could no longer be identified and was presumed to have emigrated.

One further restriction of attacks remains to be mentioned. Small infants, when they first make their appearance at the feeding place enjoy almost complete immunity. They may feed where they please and with impunity take food literally from under an adult's nose. Even a belligerent female, engaged in a furious chase of almost every other rat around the feeding place, will normally check abruptly if she encounters a babe. This immunity comes to an end rather suddenly some time during the fourth week after emergence. From observations made on the caged animals, this corresponds to a little over 6 weeks of age.

Two further points are of importance in understanding the dynamic aspects of social structure. Firstly, aggressiveness in an individual does not remain constant. Females reach a peak of aggression as young adults but as they grow older, they become less and less belligerent. They do not, however, lose rank as a consequence. An older established female may be attacked by a younger one whose aggressive propensities are nearing their maximum. She rarely retaliates in kind. More usually, she simply disregards the attack. She may withdraw very slightly for a moment but resumes what she was doing quite unperturbed. The attacker receives no stimulus to continue hostilities and in the absence of flight, there can be no pursuit. Attacks become less frequent and presently cease. The females become mutually tolerant and may even become friendly.

Table 4. Distribution of Attacks made During One Week in September 1968

\begin{tabular}{|c|c|c|c|}
\hline & $\begin{array}{l}\text { Attacks } \\
\text { by } \$ 2\end{array}$ & $\begin{array}{l}\text { Attacks by } \\
\text { o Bobtail }\end{array}$ & $\begin{array}{l}\text { Attacks } \\
\text { by }{ }^{\star} 1\end{array}$ \\
\hline On ${ }^{2} 2$ & 17 & 3 & 4 \\
\hline On sub-adults & 5 & 3 & 0 \\
\hline On juveniles & 2 & 3 & 1 \\
\hline On ${ }^{*} 1$ & $\begin{array}{l}1 \text { (intention } \\
\text { movement only) }\end{array}$ & 1 (very minor) & - \\
\hline On other males & 0 & 2 & 1 \\
\hline Total of attacks & 25 & 12 & 6 \\
\hline
\end{tabular}


Males also show a decline in activity, including hostile actions, with increasing age. They become heavy, less agile and a top ranking male is distinctly lazy. He makes his appearance at the feeding place very late and may even fail to appear at all during the early evening activity period. Since females, particularly those with litters, carry food up to the roof, the top male is presumably able to avail himself of the accumulated stores and is therefore not hungry. Although his superiority when he does appear normally remains unchallenged, his increasing laziness must make it easier for subordinates to resist being driven away and must also make it easier for an intruder to take the first steps towards entering the group.

The second important factor is appeasement behaviour which will be dealt with in detail in the next section. It is extremely effective and, if performed in time, can stave off an attack, even from a very hostile superior. A juvenile's future standing is very much a function of how he responds in early life to attacks by superiors. If he flees, he is, of course, pursued and the oftener this happens, the more likely he is to flee next time and he may become the favourite enemy of one of the females. If, on the other hand, he appeases successfully, he is not attacked and may either withdraw unpursued or even be allowed to remain where he is. Unfortunately the difficulty in identifying individual juveniles and the fact that many juvenile fights occur in the tree top hidden by the foliage, precluded any detailed study but it seems only reasonable to expect that the balance of victories and defeats in juvenile fights should not only decide the relative status of the contestants but also have some effect on subsequent responses to attacks by adults and hence on their chance of remaining within the group.

The result of the interrelationships outlined is that although attacks within the group are frequent, fights are very rare. Most aggressive moves are directed downwards in the social scale and the inferior animal does not fight back but either appeases or escapes. Pursuits are not usually prolonged, apart from the exceptional case when a female has picked on a particular individual for systematic harrying. The fights that do occur are mostly between juveniles. Although these may be accompanied by much squeaking, they are not very damaging, partly because their common location in the tree precludes the more dangerous types of fighting.

During the period of study no top male was displaced by another member of the group but one would imagine that this must happen occasionally and that it could hardly occur without some serious fighting.

\section{B. Behaviour Towards Interlopers}

A foreign rat attempting to enter the area round the feeding place is certain to be attacked by any adult members of the home group that become aware of its presence and even sub-adult females will initiate an attack. In such circumstances, the advantage is always with the home rat. The intruder is cautious and usually flees as soon as an attack is launched, although he may return again after a short interval. Even a large male is normally routed by a female, who may be very much smaller and lighter than he is. There is, however, an exception to the rule that the home rat always routs the intruder. The male tendency not to attack an adult female is very strong and operates even if she is a foreigner. A home male will often run at an intruding female but he slows down as he draws near and, if she stands her ground, may do no more than broadside her gently and desist if she still stands firm. The home female shows no such inhibition: an intruder, regardless of sex, is attacked vigorously and only rarely will a particularly large and determined male refuse to flee. The female is, in terms of numbers of attacks made, more important than the male in the defence of the territory and it is she who is responsible for keeping out foreign females. During the period referred to in Table 4, the two top ranking females made thirty attacks on strangers, a sub-adult female made six while ${ }^{t} 1$ and a sub-adult male between them made 
only three. These figures, however, do not do full justice to the role played by the top male. His attacks may be infrequent but if he does go into action they may be very prolonged and he may be the only member of the group capable of driving off a large and persistant male intruder.

When interlopers are being chased off, the limits of the territory are clearly shown. At a certain point the home rat stops short and abandons pursuit, even though the enemy is still in full flight. The stopping point $I$ regard as marking the limit of the territory and these limits remained surprisingly stable in the positions shown in Fig. 1 (p. 128), during the whole course of the study. The effect of the fence separating enclosures II and III from enclosure IV was very obvious. The fence formed the limit of the territory but when an intruder was chased out through the opening in the fence instead of over it, the pursuit extended some distance beyond and the same was true of a pursuit along the veranda from A towards B. One may infer that had the fence not been there, the territory would have extended somewhat further towards B. No pursuits leading to the main part of the courtyard beyond the enclosures were ever seen and in this region it was therefore impossible to determine the limits and no attempt was made to find their position on the roof of the veranda. The territory, thus delimited, is distinctly smaller than the foraging area. This must obviously be true if rats from $B$ commonly raided into the home area but in addition, home rats were sometimes seen at $\mathrm{B}$, or returning on the veranda from foraging beyond the territorial limits from each of the three possible directions. How far afield they actually went was never determined.

When there was a female in oestrus, the situation altered and it was only on such occasions that prolonged fighting between males was seen, with the two animals standing up to each other and neither prepared to flee. The rat on home ground no longer had automatic superiority: foreign males would no longer flee when attacked and seemed to appear in unusually large numbers, presumably attracted by the female's smell. In fact there were evenings when the ground round the home tree appeared to be alive with adult male rats, leaping at each other, sometimes three simultaneously involved, in a quite indescribable confusion. The period of fighting was, however, quite brief: it rarely lasted as much as half an hour and once mating had begun, the fighting quickly ceased.

The factors which are responsible for maintaining the integrity of the group and which at the same time permit some lability should now be apparent. The top male, despite apparent lethargy, plays an essential role. Recognition of his proximity, apparently by smell, was often sufficient to cause an intruder to withdraw. This was most clearly shown when the top male, occupied in eating, was approached from behind by the intruder. The latter, after a sniff towards the top male from a distance of 5 to $10 \mathrm{~cm}$, would turn and flee while the top male continued eating, apparently oblivious to what had happended. Moreover, a male intruder cannot establish himself in more than a very peripheral relationship unless he is capable of defeating the top male. At the same time, the chances of an intruder reaching the stage where he is prepared to fight are increased by the top male's tendency to emerge from the roof later than the rest of the group. As already mentioned, the females are responsible for the major part of routine defence. The attacks of the young aggressive females are also a factor in driving young adults out of the group and so facilitating dispersal. The peak of female aggressiveness is so timed that a young female stands a better chance than a young male of gaining a foothold inside a new group. If she fails to establish herself during this period either in her home group or elsewhere, a female is likely to remain as a peripheral raider, without true membership of any group. The sample case histories which follow illustrate the operation of the various factors which have been outlined. 
Carnera: an intruding male who took over leadership.

Carnera was a grey rat and therefore easily identified right from his first appearance in the home tree on 2 December 1967. He was by then almost as big as Pat, the current top ranking male, although his smooth coat showed that he was much younger. After a brief reconnaissance he withdrew and did not reappear until more than a month later on 14 January 1968 when he was seen briefly in the home tree, probably attracted by the smell of a female who was coming into oestrus at the time. $\mathrm{He}$ was by now distinctly larger than Pat. The following night he appeared again and although somewhat inhibited by my presence, to which he was not accustomed, he attacked several of the home males violently and knocked one off a tree branch. The next night he was seen scent marking the tree and again attacking the home males. He was victorious in every encounter. He gave way, however when attacked by Bobtail, the top ranking female. For some nights he continued thus, constantly attacking and defeating any male he met and, indeed, seeking them out to attack; but himself being driven off by Bobtail. Her attacks gradually moderated and had become very mild by the end of January. No encounter between Carnera and Pat was seen until 4 February. On that evening the two met on opposite sides of the wire netting fence. They sniffed at each other and Pat instantly fled to the roof without waiting for any hostile move: presumably he had already lost at least one fight. Three days later, Carnera was seen attempting to groom Bobtail. Although she pushed him away, she did not attack him. A little later the same evening he chased off Pat, who again fled without fighting. Bobtail continued to become less and less hostile to Carnera and by 12 February their original dominance relationship had been reversed: when she stood in his way, he threatened and she appeased, thus indicating that she had accepted his superiority. His attacks on home males had also diminished in intensity and he was no longer seeking them out to attack. When encounters did occur they now sometimes showed appeasement behaviour towards him instead of either fighting or fleeing and they were not attacked. He was clearly being accepted as a superior by the home males as well as by Bobtail. Pat, however, kept out of his way during this period and no encounter was seen until 10 days later. Pat then appeared with a bite on his nose and a little later he was attacked by Carnera. They fought violently for a few moments and Pat then fled but was not pursued. Later the same evening he was seen feeding near the periphery but thereafter he never reappeared. No corpse was ever found and it is unlikely that he was killed. Carnera was clearly quite prepared to let him escape and was not carrying on any sustained persecution. Carnera's relations with the rest of the group continued to become less tense and he and Bobtail became positively friendly but on the night of Pat's last appearance one could say that Carnera had ousted him and taken over his position as top ranking male. This had taken 10 weeks, from the time of Carnera's first serious invasion of the home territory.

Scarface: an intruding female who achieved group membership.

Scarface was a young and very active female, marked out by an old scar running obliquely across the tip of her nose, who first appeared on 18 March 1969. She fought furiously with a number of the home females, who did not succeed in putting her to flight. During the next 17 days she put in several appearances. Now, however, she behaved more cautiously towards the defenders and was chased off a number of times: at the same time, although herself an interloper, she spent a considerable time attacking and driving away other raiders. On 6 April she was again fighting furiously with all comers and was only just defeated by Matilda, the topranking female, after an encounter in which although neither animal risked a genuine attack, Scarface finally withdrew in face of threat by the home female. For the next few days Matilda 
and Scarface maintained a state of armed neutrality; when they met, there was tension but never an actual attack. The top ranking male (d 1 ) had also not yet accepted Scarface and would now and then broadside her slightly, although I never saw him actually attack her at any stage. Hostility between Matilda and Scarface gradually dwindled until by 17 April the two could meet without either expressing any agonistic tendencies and $t 1$ also now permitted Scarface to feed beside him without showing any signs of animosity. Although relations with both male and female home top rankers continued to become more amicable, one can say that by 17 April, Scarface had gained membership of the group. This had taken just a month since her first intrusion.

Notch: an intruding female who failed to achieve group membership.

Notch was first seen as an adult female on 2 November 1968. She contented herself with lurking on the outskirts, stealing food as opportunity offered. During the whole period from then until her last appearance on 4 April 1969, she never progressed beyond this stage. On several occasions ${ }^{-1} 1$ attempted to drive her away but his inhibition against attacking a female prevented him from doing more than a little gentle broadsiding. To start with Notch was able to drive off $\delta^{\star 3}$, a smaller animal, but towards the end he became her superior and chased her away from the feeding place. Throughout the whole period she was consistently chased off by the home females whenever they detected her presence and she fled at once if they attacked. Her condition gradually deteriorated and in March and April she twice appeared with a severe wound, once on the back, once on the side. Her corpse was never found but she may have fallen victim to a predator. She had remained without succeeding in penetrating the group for a period of $5 \frac{1}{2}$ months, including the time when the smaller but much more aggressive Scarface did achieve membership of the home group.

Shan: an injured female who was driven out.

This rat, an adult female member of the B group, suffered some injury to her pelvis which made her locomotion rather slow and reduced her climbing ability. As a result, she did not compete effectively for food and gradually became a more and more peripheral member of $B$ group. She made a few attempts to raid from the home rats but was always driven away. She then contracted what I believe to have been an infection of Corynebacterium arthritis and although she recovered, this left her severely crippled. She could no longer climb, was therefore forced to abandon her previous home in roof $b_{2}$ and took up her residence in a thick creeper in the courtyard outside the enclosure at B. Unable either to fight or to flee effectively she could not have survived long, had I not given her a food and water supply of her own. Living, as she did, a terrestrial existence, she was highly vulnerable and her ultimate disappearance 3 months later followed a domestic cat having taken to visiting the courtyard at night. In all, she survived for a total of 8 months from the time that her injury became apparent. Without my intervention, however, she would certainly have died some 3 months earlier from the combined effects of attacks by the other females of group B and failure to get enough food. 


\section{PATTERNS OF BEHAVIOUR}

For convenience sake the various forms of behaviour seen have been grouped into a few major categories, although it is obvious that any such grouping must be, to some extent at least, arbitrary.

\section{A. Maintenance Activities}

\section{Eating, Prey Killing and Drinking}

Small pieces of food are picked up in the mouth, then taken and held between the two paws and gnawed with the incisors, the rat meanwhile sitting on its haunches or clinging to a branch with its hind feet. The rats would even eat thus perched on the $1.6 \mathrm{~mm}$ wire (Plate II). The food is moved around in the paws now and then as it is gnawed, but the lathelike rotation characteristic of squirrel eating techniques was not seen. The pieces of food gnawed off by the incisors are passed back to the cheek teeth and chewed with a predominantly sideways movement of the lower jaw. In an adult animal the frequency of the jaw movements in chewing is approximately $3 / \mathrm{s}$. Pieces of food too large to be held in the paws are gnawed on the ground and, if necessary, steadied with one paw. When small but much prized delicacies, such as ground nuts, were available a few of the rats would take two nuts at once in the mouth and carry them off to a convenient eating place. If this was on the ground, one nut was simply laid down until the other had been dealt with. If the eating place was on a tree branch, however, the two nuts were held together in the fore paws, either side by side or one above the other and devoured in turn. At first one nut was often dropped but some rats became quite skilled at manipulating two at once. Even picking two nuts up in the mouth presented difficulties at first and I have seen a young rat using its paws to try to push the second nut into its mouth. With experience two (or even three) can be picked up neatly without assistance from the paws.

Predation was seen on a number of occasions.
When there was a flight of termites, the rats caught them on the ground or would snatch at them as they fluttered by. Moths were also captured if their flight was temporarily checked by the wire netting or when fluttering against a lit window. Cage reared animals without previous experience of insects responded at once to the fluttering of a moth or dragonfly. They emerged promptly from the nest box, chased, captured and devoured the prey. At first they showed no response to a stationary moth but with experience would detect its presence by smell and search for it. Killing of vertebrate prey was also seen. On one occasion a white mouse happened to stray into the home enclosure. It was killed at once by the first rat that encountered it, a sub-adult male, and carried up to the roof. Two bites were delivered towards the anterior end but without any very strict orientation. Small toads were killed twice. Repeated bites were made without any specific orientation as long as the toad showed any movement. Once immobilized, it was carried up to the roof. This toad killing seemed to be exceptional: toads were often about in the enclosure but, apart from these two incidents, I never saw them molested. An unsuccessful attempt to capture a small skink was also seen but when a large male rat running down the tree met a full grown male Agama agama coming up, both first drew back and the rat, after smelling at the lizard, jumped across to the next branch to continue his journey. At one period a family of voles (Arvicanthus niloticus) lived in enclosure II and used to attempt to raid the feeding place. They were attacked and chased off but not killed although undoubtedly the rats were physically capable of killing then. Presumably both the Agama and the voles were too big to be treated as prey and only the vole was treated as an intruder: possibly the fact that the voles did steal food may have been a relevant factor in their being attacked. A freshly killed small snake evoked no alarm but was treated as food and 


\section{P LA TE I}

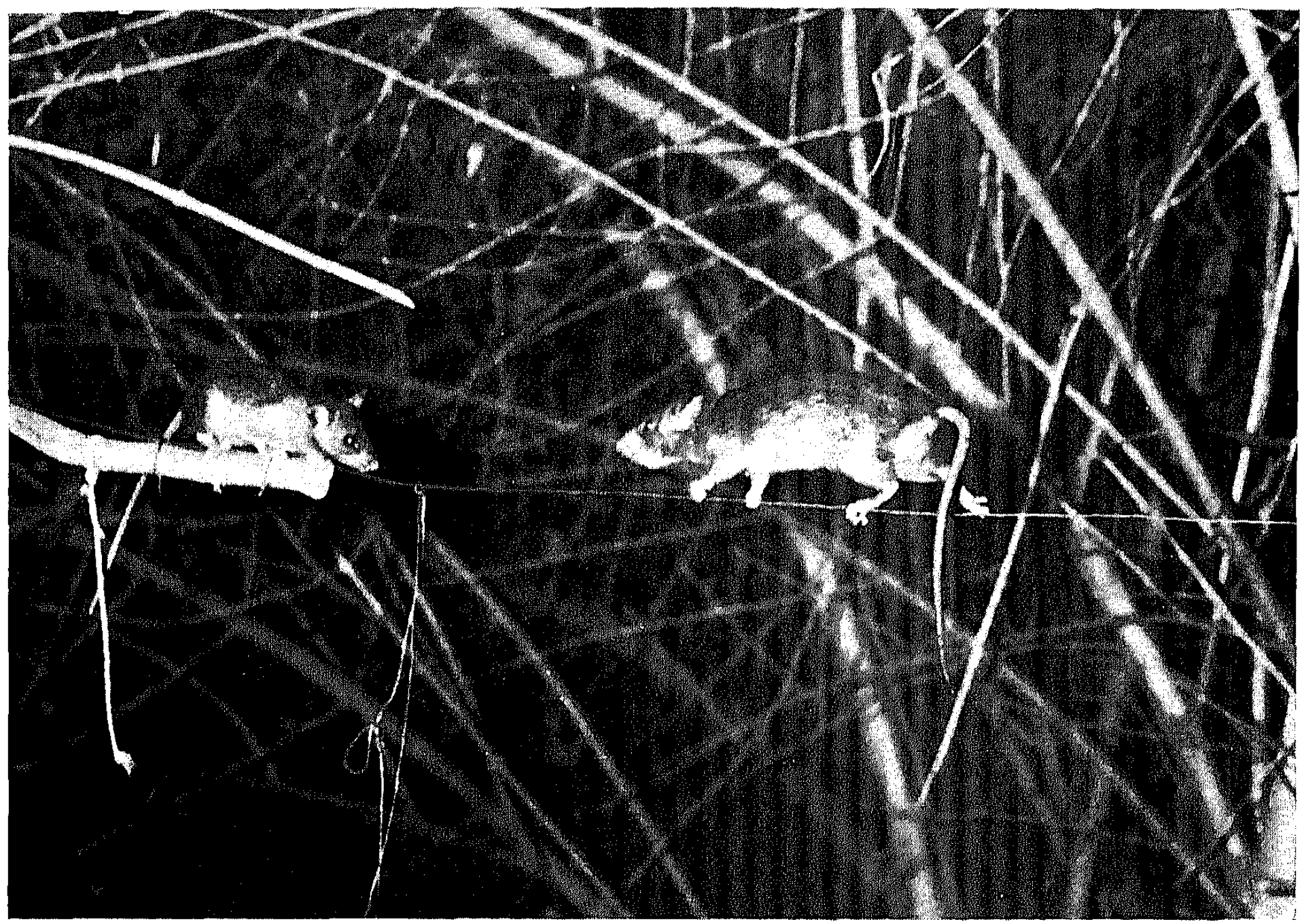

A rat running along 1.6-m diameter wire (note use of tail). 


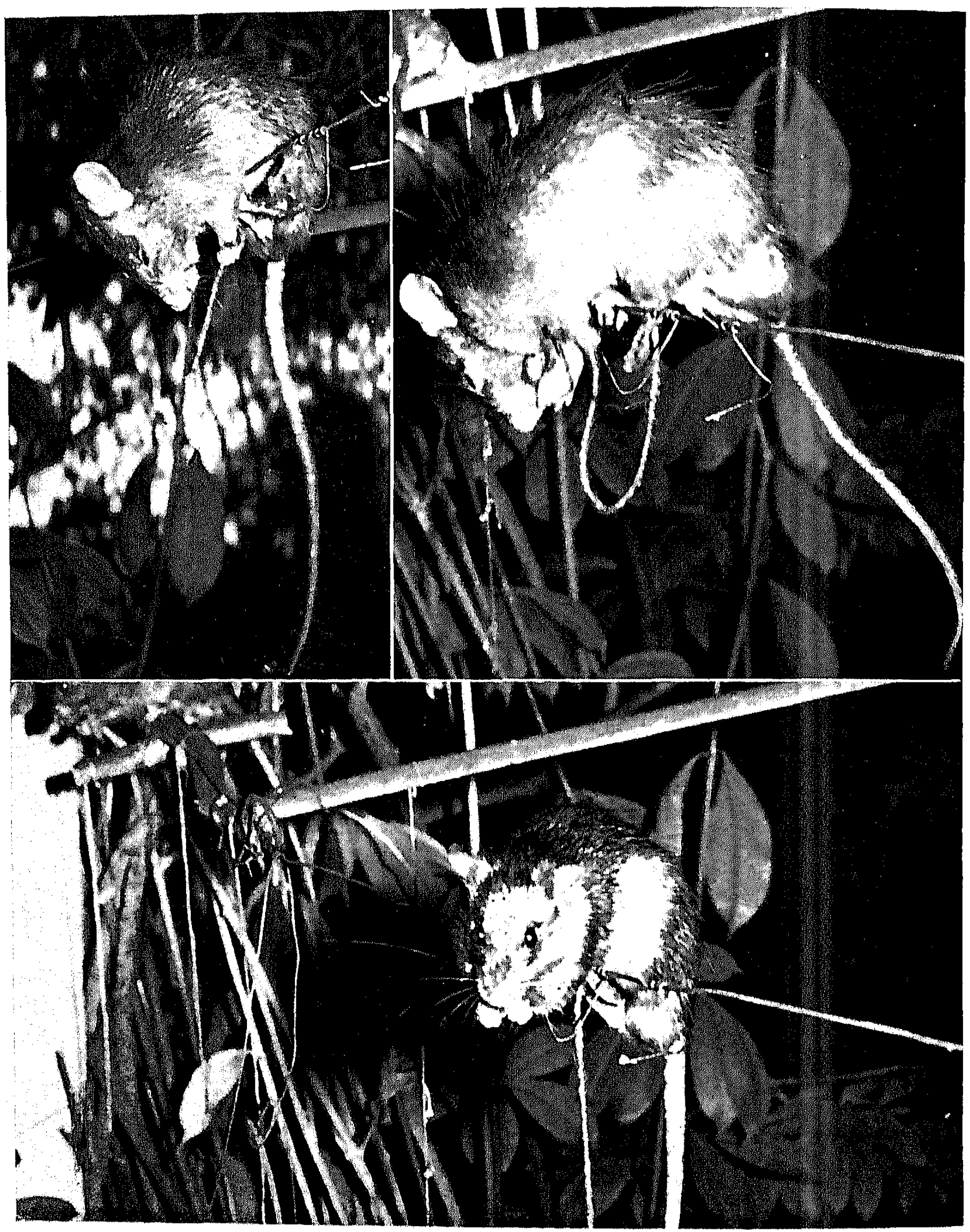

A rat pulling up a string (top left), removing the nut (top right) and eating the nut while perched on the wire (bottom). 
carried up to the roof.

Small food objects were eaten wherever they were found, provided the rats were fully at ease, otherwise they were usually carried only a little distance before being consumed. Larger things were almost always carried to the roof, even at the cost of considerable effort. In the cage small amounts of food were regularly taken to the nest boxes but systematic hoarding was practised only by females rearing litters. Such animals would amass a considerable pile of food, not in the nest but on the shelf close beside it.

In view of its interest from the point of view of the evolution of hoarding, a few simple tests were made of the treatment by the freeliving rats of pieces of food of different sizes. Bits of cassava and banana were used, in three sizes. The former were cubes of side $2 \mathrm{~cm}$, blocks $2 \times 1 \times 1 \mathrm{~cm}$ and $1 \mathrm{~cm}$ cubes. The pieces of banana were approximately $2.5 \mathrm{~cm}$ in diameter and $2 \mathrm{~cm}$ long and were either left whole, halved or quartered. Two pieces of each size group of one type of food were put out each night. Some vanished unobserved and cases where a rat occupied with the food was chased or disturbed by another were discounted. The results are shown in Table 5. The effect of the size of the piece of food is obvious: all of the large pieces and none of the small ones were taken to the roof, while the middle sized pieces might be treated either way or in an intermediate manner.
Water dishes were provided at both feeding places and the rats drank regularly, usually after first having eaten for some time. A single drink sometimes took over $3 \mathrm{~min}$ but from $\frac{1}{2}$ to $1 \frac{1}{2}$ min was more usual. For 163 timed undisturbed first drinks of the evening during 1967 to 1968 the mean time taken was $1 \mathrm{~min} 16 \mathrm{~s}$. Drinking was most frequent during hot; dry weather and as can be seen from Fig. 3, the
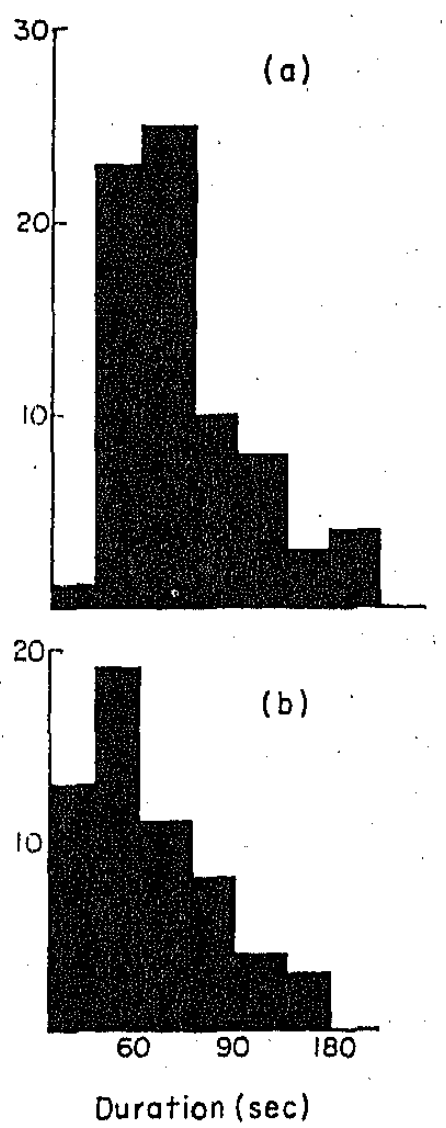

Fig. 3. Duration of first drinks; (a) for the hot dry months, January to March 1968; (b) for the rainy months, May and June 1968.

Table 5. Treatment of Pieces of Food of Different Sizes

\begin{tabular}{|c|c|c|c|c|c|c|}
\hline \multirow[b]{2}{*}{ Treatment } & \multicolumn{2}{|c|}{ Large } & \multicolumn{2}{|c|}{ Mẹium } & \multicolumn{2}{|c|}{ Small } \\
\hline & Banana & Cassava & Banana & Cassava & Banana & Cassava \\
\hline Eaten on the spot & 0 & 0 & 0 & 2 & 2 & 9 \\
\hline Taken part way up tree & 0 & 0 & 3 & 3 & 3 & 1 \\
\hline Taken to roof & 9 & 6 & 2 & 4 & 0 & 0 \\
\hline Mean score* & \multicolumn{2}{|c|}{$2 \cdot 0$} & \multicolumn{2}{|c|}{$1 \cdot 3$} & \multicolumn{2}{|c|}{0.3} \\
\hline
\end{tabular}

* Mean Scores in bottom row show the average response to food of different sizes. Each mean was based on scoring 0 for pieces of food eaten on the spot, 2 for those carried right to the roof, and 1 for those carried part of the way up the tree before being eaten. 
duration was also longer in January to March (hot dry months) than in May and June (after the rains had started).

\section{Toilet Behaviour}

The caged rats performed their longest toilets shortly after emerging from the nest in the evening and before coming down for food. Presumably the same was true of the free population, for although the rats often sat in the tree and indulged in short bouts of grooming or cleaned their paws and faces after a meal, long toilet sessions were not seen.

The methods of cleaning are in general similar to those described for Cricetomys (Ewer 1967) and differ mainly in the way the hind leg is used in scratching. In both species scratching is a major component of grooming and a bout of scratching consists of several 'scratch series', punctuated by licking the toes. In Rattus, however, I did not see the long alternating bouts of hind leg scratching and cleaning of the whole foot which are characteristic of Cricetomys. Instead, a single bout of scratching (with the usual toe licking interspersed) is generally either the terminal action of the grooming session or heralds a return to cleaning the face and paws -the usual starting point of the toilet. Rattus moreover uses the hind foot to scratch the chest and axilla: the ipsilateral forearm is raised to facilitate the process, the animal meanwhile supporting itself on the contralateral fore and hind limbs. In Cricetomys the fore arm is not raised in this way and three limbs always support the body when scratching with the hind foot is in progress. In addition, there is a difference in the way the tail is held while being cleaned by the mouth. Cricetomys may hold the section of the tail on which it is working either horizontally, with the two paws gripping it from the same side or vertically, with one paw on either side. In Rattus I never saw the latter method used and the tail was always held horizontally.

As in Cricetomys, the various grooming actions are not carried out in a fixed order, but neither are they random. No exhaustive study of toilet behaviour was made and Table 6 summarizes the sequences recorded and shows the most probable ordering for Rattus rattus compared with that for Cricetomys. Both the basic similarity and the way the differences relate to hind leg scratching are obvious. These differences could relate either to differences in fur texture or in body build in the two species and it would be interesting to have comparable data for wild Rattus norvegicus and for Cricetomys emini.

\section{Defaecation and Micturition}

Neither in the wild population nor in the cages did I ever see any particular behaviour associated with defaecation. Pellets were dropped at random, the animal often not even pausing in its other activities. I never saw micturition taking place and there was no evidence of urine ever being used as a marking or trail laying substance.

\section{Nest Building}

The caged animals readily carried in to their nest boxes any suitable material provided: leaves, grass, bits of paper or cloth. They also cut off the thinner twigs from the tree branches with which their cage was furnished, making a very clean oblique cut and carried these in. Both sexes carried in bedding but females were more active in this respect than males, particularly when rearing litters. The nesting material was always picked up and carried in the mouth without any use of the paws. When she was rearing a litter, a female generally blocked up the entrance to the nest box, twigs being particularly favoured for this purpose and when she left the nest she would pull the bedding over her young so as to cover them completely. In the wild population females were seen cutting twigs from the home tree and carrying them into the nesting area in roof $a_{1}$ (Fig. 1, p. 128), but I did not see males doing this.

\section{Digging}

In the wild I saw digging only a few times and 
Table 6. Toilet Sequences of Rattus rattus

Succeeded by

\begin{tabular}{lllllll}
\hline 0 & Face and paws & Body & $\begin{array}{c}\text { Hind leg } \\
\text { scratch }\end{array}$ & Foot & Tail & Total \\
\hline
\end{tabular}

0

Face and paws

Body

Hind leg scratch

Foot

Tail

Total

-

3

3

5

0

0

11
7

$-$

26

5

0

4

42

0

36

4

0

1

2

0

42

2

3

1

2

0

13

5

- 1

1

0

6

13

7

6

118

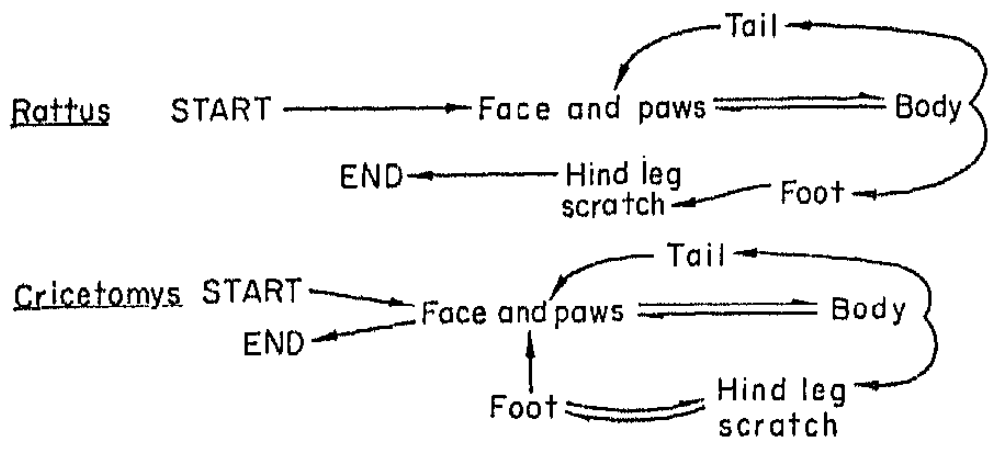

in each case the animal was clearing a routine pathway that had become partially blocked with soil. Rats living elsewhere also dug their way into an enclosure in order to reach food placed inside for other animals. The caged rats regularly excavated tunnels in the hard earth mounds which surrounded the bases of their tree branches, possibly in an attempt to escape from confinement.

The actions used in digging include most of the normal rodent repertoire. Most of the work is done by scraping very rapidly and somewhat asynchronously with the two fore paws. The earth is thrown out behind and every now and then the animal moves back a little and kicks away the accumulated pile, using the two hind feet simultaneously but not quite synchronously. Once a large excavation has been made, the rat may work from inside and push the soil out before it with the fore paws but I never saw the nose used to 'bulldoze' soil away, as the broader snouted Xerus sometimes does. Finally, lumps of earth or stones may be picked up in the mouth and carried outside. Obviously if no other refuge were available, Rattus rattus would be perfectly capable of digging a burrow, and Worth (1950) has found this species occasionally occupying burrows.

\section{Anxiety and Alarm Behaviour}

General. Black rats are extremely vigilant animals. If they are slightly suspicious or uncertain they will rise on the hind legs, peering and sniffing towards any possible source of disturbance. A strange object is approached very cautiously, in the manner typical of small mammals: the body is held low, with the hindquarters especially pressed close to the ground and a number of partial withdrawals are usually 
made before the object is actually contacted and sniffed over. At any sudden movement or noise, they instantly flee to safety and even the handreared animals showed this type of behaviour. Fleeing is contagious and if one or two rats run rapidly up the tree, the rest either follow or dart into a nearby refuge. In fact an animal merely taking food up the tree to eat in safety sometimes creates a false alarm and triggers off a general retreat.

Leaping. A second type of alarm behaviour, which is usually the response to some sudden movement close at hand, is to leap vertically in the air. If many animals are close together, this behaviour tends to set up a chain reaction: an alarm leap by one rat startles his neighbour who also leaps and one may thus get a sudden outburst of vertical leaping. How frequently this happens depends on the general situation within the group at the time. It is usually seen only if one or more young females are present at the peak of their aggression. 'Jumpiness' is a sign that the animals are nervous and the most common reason for this is a high level of aggression in at least some of the members of the group. In such circumstances unprovoked attacks are common-place and the rats are metaphorically as well as literally 'jumpy.' A sudden movement nearby is likely to presage attack and the vertical leap is a means of evasion when there is not time to flee (it may then be called an evasion leap) but it also serves if there is not time even to locate the source of danger accurately (an alarm leap). Similar jumping by Xerus in response to a nearby rustling noise has been interpreted as defensive behaviour against snakes (Ewer 1966). The evasion leap in response to an attacking rush which is seen is extremely effective. The attacker misses its strike and passes harmlessly beneath the intended quarry. I once saw a young male rat at the feeding place evade three successive attacks by a female in this manner: each time she ran at him, he leaped and she passed beneath and took some time to locate him again. In the end she lost track of him when he finally went up the tree. Similar evasion leaping has been described by EiblEibesfeldt (1953).

Tooth gnashing. Tooth chattering or gnashing is a characteristic accompaniment of hostile encounters in a great many species of rodents and is usually regarded as a threat signal. In Rattus rattus, however, it has a different significance. In the free-living population, out of thirty-four gnashing incidents recorded, thirteen were responses to an unfamiliar noise, ten to unfamiliar movements or smells and one more was also an accompaniment of alarm; to seven no cause could be assigned while only one occurred in an agonistic situation. Of all the hundreds of attacks witnessed amongst the freeliving rats, not one was preceded by gnashing, nor did gnashing occur in association with those actions that did function as threat. In the incident just referred to the female, Bobtail, had attacked a male much larger than herself who stood firm and refused to flee. She drew back a little, then again moved towards him; he turned broadside, indicating that he was still prepared to stand his ground and she then ran half way up a nearby creeper and gnashed before continuing her retreat to the roof. A captive female also once gnashed in association with attack but the circumstances were abnormal. A smaller female had been placed in error in the large cage, together with an older female who had been in occupation for some time. I was not present when the intruder was first attacked but when I came on the scene, the latter had been badly bitten on the side, the wound subsequently proving fatal. The resident female chased the intruder, who fled from the tree to the ground and there remained crouching. The resident female then sat on a tree branch and gnashed repeatedly, moved lower and again gnashed. The intruder, caged in and therefore unable to flee, moved slowly over to the cage door and I removed her. The gnashing of the resident rat seemed to be an expression of anxiety or frustration, because a thoroughly defeated intruder failed to disappear.

It thus appears that in Rattus rattus gnashing 
is normally an expression of alarm rather than a threat. The exact circumstances that elicit gnashing are, however, not easily defined. It is not the common response to sudden noise or movement but seems rather to relate to something unfamiliar and a rather delicate motivational balance appears to be involved. A slight scare will not evoke gnashing and a very severe one will merely result in precipitate flight. Gnashing was not contagious and I never heard more than one rat at a time do it. It was rarely possible to see which animal was gnashing but out of the seven times when this could be done, it was a female who was responsible six times and a sub-adult the seventh.

It would, of course, be of interest to know whether gnashing by one animal acts as an alarm signal to other members of the group. Unfortunately I was never able to elicit gnashing predictably and never succeeded in recording it, so that play-back tests were impossible. It is, however, true to say that if one animal gnashed, the rest all either fled instantly to the roof or froze where they were for a whi'e before doing so: moreover, they remained in hiding for much longer than would have been the case after a routine 'scare'. One might obviously argue that this behaviour was not a response to the gnashing but to the disturbance that had caused it. Three incidents suggest that this is not the case and that gnashing does act as an alarm signal. On the first occasion Bobtail was attempting to screw up her courage to take a nut from my fingers. After much hesitation she at last moved just close enough to touch my hand but at the last moment she fled back some distance and gnashed. All the rats present promptly fled, although there had been nothing to disturb them and the 'scare' was confined to Bobtail herself. In the second incident a leaf from the tree fell on the ground close beside a feeding rat. It made no significant sound but the rat gnashed and all the animals in the neighbouring tree fled to the roof. On the third occasion a rat on the roof suddenly gnashed. Although no other cause for alarm was audible or visible below, all the rats at the feeding place either froze where they were or fled.

\section{B. Routine Social Interactions}

\section{Agonistic Encounters}

Although the patterns involved in attack and defence are relatively simple, the various ways in which they may be combined produce considerable diversity in the behaviour seen in hostile encounters. Moreover, the female in repulsing the sexual advances or investigations of the male uses a number of the same patterns as appear in simple hostile encounters. The two situations are, however, rather different. The latter will therefore be dealt with first and the former will then be described separately at the end of the section.

It must be borne in mind that the numbers quoted refer only to encounters where the contestants were identified and the whole situation was clear. They are therefore much smaller than the total number of incidents that took place but do reflect the relative frequencies of the different types of interaction.

Attack. High intensity uninhibited attack consists of a swift direct run towards the opponent, with the mouth slightly open in readiness to bite. If the opponent does not flee, the attacker usually leaps at his shoulder region, biting and striking with the fore paws. If the attack is launched from close quarters, a swift lunge or leap at the victim replaces the run.

Rolling and wrestling fight. The two rats lunge at each other and roll together on the ground, clutching or striking at each other with their paws and although they also attempt to bite, 'bites at', which are not carried home, are commoner than true bites. Even if there is a genuine bite, there is no hanging on: the bite is very swift and the release instantaneous.

This is the most violent form of fighting and I saw it only six times: twice between juveniles, once between two highly aggressive young adult females and three times between adult males. Two of the latter fights were between a top male and a challenger in the process of displacing 
him. The third was accidental: a large male knocked a smaller one off the top of the wire netting, lost his balance and fell with him to the ground, where the two fought briefly. No heterosexual fight of this type was ever seen.

Jump-fights and single jumps. In a jump-fight the two rats face each other and leap vertically in the air, sometimes as high as their own body length clear of the ground. They may strike at each other with their paws but often they do not contact each other at all. In some situations one animal may make a single leap in face of an opponent.

Jump-fights most commonly occur in the contests between males which take place when a female coming into oestrus is present. The number of such jump-fights between males was not recorded, since many were often taking place simultaneously and counting was extremely difficult. Apart from this, the characteristic situation, the jump-fights seen were as follows: female/female, three (one preceded by wrestling); juvenile/juvenile, one (followed by wrestling); female/male, three. Heterosexual jump-fights are exceptional and the three recorded all happened in slightly peculiar. circumstances. In two of them a home female chased a male raider who first fled, but finding his route checked by the wire netting fence turned and faced his pursuer and a jump-fight followed. The third incident might be regarded as a case of redirection. A male, in an excited condition after chasing off another male, came face to face with a female and jumped. She responded in the same way and a brief jumpfight followed.

The vertical jump as a means of evading attack has already been mentioned. Single jumps also occur as a normal action in hostile encounters when an attacking rat makes a high intensity onslaught on an opponent who does not flee. This was seen a number of times when a female attacked a male bigger than herself and he simply stood his ground firmly. The female then checked her run just before contact was made. executed a single jump and then moved off.
A similar single jump was once seen executed by a home male who ran at an intruding female. She turned towards him and reared up and the male made a single jump and left her. In this latter type of situation the motivation appears to be the same as in a genuine jump-fight. The level of aggression is high but if the opponent does not flee, then he cannot be chased and the vertical jump replaces pursuit.

A jump-fight may terminate abruptly with one of the animals running away. I could never see what decided who was the victor, since these fights appeared to be completely harmless. Possibly the number of times he is willing to jump is a function of the rat's level of aggression and the loser is simply the less aggressive. If this is correct then the high-intensity sex fights between males which often take the form of jump-fights, provide a stylized type of contest which decides who is the more highly motivated without injury to the loser. On one occasion when sex fighting was in progress three males became simultaneously involved in a jump-fight. To a naive onlooker, their behaviour would have suggested some curious form of country dancing, rather than a contest whose outcome might decide which rat finally had access to the oestrous female. If two contestants were equally matched and neither ran then, after a series of jumps of diminishing vigour, they might go over into a boxing fight. A jump-fight, needless to say, can occur only on the ground.

Boxing. In a boxing fight the contestants, reared on their hind legs, strike out at each other with their paws. They may also attempt to bite but, as in rolling and wrestling, most bites are only 'bites at'. Boxing fights are often accompanied by shrill squeaking, juvenile fights being particularly noisy.

Boxing fights may occur between any pair of more or less evenly matched animals-juvenile against juvenile, male against male, female against female, and female against male-but I never saw a sub-adult stand up to a full adult and box against it, nor a juvenile to a sub-adult. The factors that determine victory are more 
obvious in a boxing fight than in a jump-fight. The winning rat makes more attempts to bite and strike with the paws than the one who is losing and it is the loser that does most of the squeaking. Boxing may terminate by one animal dropping to all fours and retreating; it may pass over into the reared up 'paws-on' posture (see below) or the two may drop to all fours and continue the fight by broadsiding. Although most boxing fights occur on the ground they may also take place in the tree, particularly if between immature animals. Out of seventeen boxing fights where the details were recorded, five took place in the tree.

Rearing up on the hind legs, the preparatory movement for boxing, may sometimes prevent an attack or cause an inferior to retreat. Although itself a defensive rather than an aggressive action, this posture can therefore act as a threat. For example when a young male approached the top ranker the latter reared up and the young male fled. Similarly on three occasions the top male responded in the same way to a non-oestrous female whom he was approaching in a hostile manner: she turned and reared up and he at once withdrew. As will be described later, both boxing and rearing are commonly used by a female in repulsing the courtship advances of a male.

Reared up paws-on. In this posture the contestants stand reared up facing each other, as in boxing, but instead of striking at each other, they place their paws on each other's shoulders. The heads are close together, sometimes with the mouths in contact. The rats may either remain for two or three seconds thus immobile before dropping to all fours, or they may walk on their hind legs for some distance, the larger and heavier animal usually advancing and the smaller moving backwards.

Paws-on is most commonly seen in a sexual context but it does occur in other situations. It was recorded once between two juveniles as a transition from boxing, once between a male and female and once between a female and a juvenile when the latter inhibited the female's attempt to box him off by appeasing (see below). Although it most usually takes place on the ground, one sexual paws-on was seen on a tree branch.

Broadsiding. In broadsiding one rat approaches another, turning sideways as he does so and then pushes against his opponent with his side and hindquarters. This may be a single action, used to make the opponent move away, or it may develop into a broadsiding fight with the contestants pushing against each other in the broadside position. The vigour of the contact can vary all the way from a gentle shove to a violent blow, capable of knocking the opponent off a tree branch.

Broadsiding is the commonest of all hostile interactions and it is by far the easiest for the rats to adopt if they are on the branches of the tree, where wrestling or jump-fighting are out of the question and even boxing is difficult for heavy adults. In the tree a high intensity broadsiding fight takes the form of each rat trying to get above his rival and push him downwards. A rat may chase another from the ground to the tree, where the latter may refuse to flee further and a fight develops. The attacker, advancing from below will first broadside the opponent upwards for a few seconds, then scramble round to get above him and drive him downwards. It was only in the tree that prolonged broadside fights were seen and it was clear that had the animals been on the ground, they would have adopted one of the more violent forms of contest; boxing, jumping or even wrestling and rolling. Broadsiding, however, may also be used merely to get another rat out of the way-either in defence of food or because he is obstructing free passage. The latter situation, of course, frequently arises in the tree, where one rat traversing a branch may meet another coming in the opposite direction. Broadsiding encounters were therefore subdivided into three categories:

(1) In the tree.

(2) Pushing an opponent on the ground out of the way or away from food.

(3) Residual ground encounters. 
Table 7. Distribution of Broadsiding Encounters

\begin{tabular}{|c|c|c|c|c|c|c|c|}
\hline & \multicolumn{3}{|c|}{$\begin{array}{l}\text { Female initiated } \\
\text { against }\end{array}$} & \multicolumn{3}{|c|}{$\begin{array}{l}\text { Male initiated } \\
\text { against }\end{array}$} & \multirow{2}{*}{$\begin{array}{l}\text { Immature } \\
\text { initiated } \\
\text { against } \\
\text { immature }\end{array}$} \\
\hline & Male & Female & Immature & Male & Female & Immature & \\
\hline (1) In tree & 23 & 20 & 7 & 33 & 17 & 10 & 5 \\
\hline $\begin{array}{l}\text { (2) Defence of food or clear- } \\
\text { ing passage on ground }\end{array}$ & 13 & 15 & 19 & 8 & 6 & 13 & 2 \\
\hline \multirow[t]{2}{*}{ (3) Residual, ground } & 15 & 11 & 1 & 18 & $\begin{array}{c}25 \\
(13+6+6)\end{array}$ & 6 & 0 \\
\hline & 51 & 46 & 27 & 59 & 48 & 29 & 7 \\
\hline
\end{tabular}

Only the last category consists of hostile encounters not biassed either by the physical situation or by some specific desideratum-food or free passage. The data are summarized in Table 7 and the three categories will be considered separately.

(1) Broadsiding in the tree. This may occur between any more or less equally matched category of animals and, in addition, adults will broadside sub-adults or juveniles. Females will readily make broadside attacks on opponents of either sex but prolonged fights are commoner with other females than with males. This is probably largely because it is difficult for the lighter female to win a fight of this type, where weight counts for so much, against a male and she therefore quickly gives up. The twentythree attacks made by females on males included only two prolonged fights, while there were six fights amongst the twenty attacks made by females on females. The attacks of males, on the other hand, are directed against their own sex much more commonly than against females. Of the seventeen broadsides initiated by males against females, three were incomplete -little more than intention movements; one was a purely defensive response when a female ran at him and there were no prolonged fights.

(2) Broadsiding on the ground to clear a passage or to prevent access to the food. Here the major category is broadsiding of immatures by adults of both sexes. Females did more defence of food than did males and attacked adults of either sex quite indiscriminately. The data for males are too few to say definitely whether they show a tendency to avoid pushing females aside.

(3) Residual ground broadsiding. This is in many ways the most interesting category, since it represents what may be regarded as uncomplicated hostile encounters. The figures for male initiated broadsides against females given in Table 7 are misleading without further analysis. They suggest a tendency to direct broadsides preferentially against females, a contradiction of what was found for broadsiding in the tree. However, of the twenty-five cases, thirteen were retaliatory responses to some other type of attack by the female, while in six cases the female broadsided was not a home rat but an intruder. No home female was ever seen to broadside an intruding female; instead their attack was always of the full scale high intensity type. The fact that a male will use the much less violent broadside against a female intruder is therefore itself a reflection of his strong tendency to refrain from attacks on a female. This leaves only six male-initiated broadsides against females which are strictly comparable with the eighteen directed against males and the fifteen female initiated broadsides against males. There is therefore no contradiction with the results for arboreal broadsides.

Broadsiding is an action which strongly suggests conflicting motivations. The conflict, however, is not the classical one between fight and flight. Broadsiding is most usually an 
aggressive rather than a defensive action and it is used in situations where there is absolutely no reason to suggest any readiness for flight: for example, an adult broadsiding a juvenile away from food or a home male chasing off an intruding female. What is common to all the situations in which broadsiding occurs is motivation for attack, combined with some inhibiting factor, whether it be the physical limitations imposed by having to cling to a tree branch, the fact that the opponent is a female or that to launch a full attack would interrupt one's own feeding. The origin of broadsiding would therefore seem to lie in a tendency to attack combined with inhibition of attack, rather than with any tendency to retreat. Blurton Jones (1968) postulated a similar conflict between a tendency to advance and to 'stay-put' rather than to flee, as the basis for one of the displays of the great tit (Parus major).

Kick off. A kick with the hind leg is sometimes used to avoid or to terminate a contact. If one animal is following the other, the kick is delivered backwards against the head or shoulders of the follower. In the broadside orientation the kick is delivered sideways against the opponent's hindquarters. Sometimes the kick is aimed rather high and the foot passes up over the opponent's body, so that the action looks rather like an ill-oriented mounting attempt. This is particularly so if the kick, as not infrequently happens, is delivered rather weakly and not decisively. The common association with broadsiding does not indicate any close central nervous linkage of the two motor patterns but merely reflects that fact that, apart from sexual following, broadsiding is the only situation that arises where the two animals are oriented in such a way that a kick can be delivered. In the sexual situation kicking usually occurs without broadsiding, while of the 267 broadsides recorded in Table 7, only nineteen ( 7 per cent) were accompanied by kicks. In the tree, where kicking would make the foothold less secure, only three out of 115 ( 3 per cent) broadsides were accompanied by kicks while on the ground the figure was sixteen out of 152 (11 per cent). The difference is significant: $\chi^{2}=6.2, P<0.02$. Kicking appears to be a purely defensive action and in sexual following is associated with the female attempting to walk away from the male, not with her turning to box him off.

Push off. In addition to the kick off, contact may also be avoided by pushing the partner away with both forepaws. This ranges from a gentle shove to a vigorous strike, distinguished from a close-quarters full attack only in that the action is usually initiated from a squatting on the haunches posture and is not followed by further aggressive actions.

Pushing off is most commonly used by adults to drive away younger animals, generally in defence of food. This category accounted for thirty-four out of a total of fifty-two recorded incidents. It is much more commonly used by females than by males: thirty-one cases of females pushing off younger rats were recorded, as against only three for males. These facts reflect the greater ferocity of females in defence of food which has already been noted in relation to broadsiding.

Hustling. A rat may sometimes cause a smaller individual to withdraw by a process which falls short of actual attack, merely by walking briskly towards it and, if necessary even contacting it. If the inferior does not move far enough, the process may be repeated two or three times, The procedure is reminiscent of what is called 'buzzing' when referring to the behaviour of aircraft.

Flight and pursuit. A rat fleeing from a pursuer normally runs 'home'. For an intruder this means leaving the territory that is foreign to him as fast as possible. As already mentioned, the pursuing home rat normally halts at the territorial limit and the quarry is allowed to escape. Members of the home group when fleeing normally run up to the home roof. This may entail some circling about on the ground before one of the routes to the roof can be safely reached. It is quite common for the 
pursuer to lose track of the quarry and be diverted into mistaken chasing of some other rat that happened to cross its path, which is abandoned as soon as the error is recognized. Only once did I see a home rat cut off from all routes to the roof and chased along the veranda. When he reached the limit of the home territory he tried to turn back but was again chased away. He circled back from the invisible boundary three times before he finally succeeded in dodging past his pursuer and reaching one of the creepers that led to the roof. Pursuits within the group are rarely prolonged but occasionally there is a persistent chase and the quarry is followed up the tree, where the chase may go to and fro among the upper branches. In the tree a rat may evade a pursuer by running down one branch and then doubling back up another. The pursuer will usually run straight on past the fork and thus lose track of the quarry. I have also seen cases where the pursuer lost track temporarily, then came on the pathway just traversed by the quarry, sniffed it and followed the trail in the wrong direction. The inefficiency of visual following which was apparent in these pursuits operates in favour of the fleeing animal who, in the end, almost always succeeds in escaping.

\section{Repelling by Females of Male's Sexual Advances}

During sexual following the motivations of the animals are not those of an ordinary hostile encounter. The female is much less aggressive than at other times and will permit even a small male to approach her. Her actions are primarily defensive and do not include vigorous attacks. The male is virtually devoid of aggression: only in one out of nineteen followings did I see any hostile action initiated by a male and this was no more than a very slight broadside as he approached an unusually aggressive female. Approaching the female, the male attempts to make contact with her and to smell her vulva. She may either merely attempt to evade him or she may turn round, rear up and box him off or push him away with her paws. The male does not retaliate but attempts to groom the female's head and face. In doing so, he may restrain her attempts to drive him off by clutching the fur of her shoulder's in one paw and holding her at arm's length, at the same time reaching forward with his head to groom her. If she refuses to be pacified and continues to push or box him away, the male may desist and retire temporarily. More usually, however, the female ceases boxing, turns away and moves forward again, sometimes with an intervening period when the two stand or move in the reared up paws-on position. A male following closely and nuzzling at the female's vulva, or attempting to pull up her hindquarters with his paws in order to do so, is often pushed away with a hind leg kick off. Less commonly a female may broadside a male away but this is usually associated with the more aggressive boxing rather than with the defensive kick. In nineteen followings where the male was being repelled, the actions used by the female occurred with the following frequencies: boxing, eleven (leading to paws-on three times); kick off, nine; broadside, five; push off, two; jump-fight, one, this exceptional jump-fight involved the female already mentioned as being unusually aggressive. Possibly she was at a very early stage in the development of oestrus.

\section{Threat Behaviour}

The way in which rearing up can sometimes act as a threat has already been described. In addition, both pilo-erection and the gait (sometimes held as a posture without locomotion) which I refer to as 'stegosauring' appear to act as threat. Both are usually but not invariably combined with turning broadside. Pilo-erection can occur virtually instantaneously and causes not only an increase in apparent size but also a sudden alteration in contour, from a smooth to a ragged outline. Stegosauring consists of moving about (or standing) with the hind legs much extended so that the hindquarters stand much higher than the shoulders. Both are extremely obvious, especially in side view: even though form vision may not be very well 
developed in Rattus rattus, it is difficult to believe that such behaviour could escape the notice of a nearby conspecific. I have, in fact, seen a number of incidents where each type of behaviour has caused inhibition of an intended attack or fleeing. One example of each follows:

(i) On the veranda (and therefore less confident than within the home enclosure) an aggressive female moves towards a home male whom she often harries. She broadsides him slightly and kicks him. He moves back a little, stegosaurs and turns broadside. She draws back, then approaches again. He again turns broadside and she stops. He moves slightly towards her and she retires.

(ii) A big male running up the tree finds a smaller male in his way. He bristles up and turns broadside and the other turns and flees.

In considering the motivation for these two forms of threat, two points must be borne in mind. Many examples of complex threat behaviour which have originated in a conflict situation are commonly regarded as having undergone emancipation during evolutionary elaboration. This will not be likely to occur all at once and in different cases various degrees of emancipation may therefore be found. Blurton-Jones (1968) suggests as one such intermediate a condition where a display occurs in response to attack-evoking stimuli whenever these do not actually produce attack, regardless of what may be the factor which prevents the attack. A second point is that even if a display is emancipated and has acquired new motivational relations it may still also be evoked in the original conflict situation.

Blurton-Jones' suggestion appears to be exactly applicable to stegosauring. This pattern is often shown in situations where the animal circles towards and away from the potential object of attack and its whole behaviour suggests that attack is inhibited by stimuli which produce fear or a tendency to retreat. It also occurs, however, when the animal has been attacking, appears to be ready to go on doing so but is thwarted by the absence of an opponent and also in cases when a male is inhibited by the fact that his opponent is female. Of thirteen recorded cases of stegosauring, four fell into the first category, six into the second and three into the last. One example of each will suffice:

(i) An intruding male has been fighting back when attacked and refusing to flee: he finally hides under cover of thick vegetation from the home top ranker and the latter goes up the tree. The intruder then moves after him, circles towards the tree and away from it, stegosauring and bristling.

(ii) An aggressive female, having successfully chased out all raiders, walks about stegosauring. As soon as an intruder returns, she launches a high intensity attack.

(iii) An aggressive home female attacks the intruding male (Carnera) who has already established superiority over all the home males. Although much bigger than she is, he does not retaliate but stegosaurs and turns slightly broadside.

Bristling is more complex than stegosauring. It certainly does occur in conflict situations, often together with stegosauring, but it also happens when a larger male, by bristling, puts a smaller one to flight, when one can see no reason for fear or inhibition on the part of the bristling animal. In another incident where there was no indication of fear, a sub-adult male stared fixedly at another, bristled suddenly and ran at him in a full scale uninhibited attack. In another case a prolonged broadsiding fight between two females was taking place in the tree. Now and then they drew apart and paused for a moment: one rat would then suddenly erect her hair and make a vigorous new attack. It was always the attacker who did this and the pilo-erection preceded the attack very briefly. The victorious intruding animal referred to in (iii) above was also seen to bristle just before launching a violent attack on the erstwhile top ranking home male. Out of twenty-five cases of bristling, seventeen were explicable in terms of obvious conflict, the other eight were not. 


\section{Appeasement}

In the behaviour which I call 'appeasing' an animal approaches a superior with hindquarters low, neck extended and ears usually laid back and attempts to bring his mouth in contact with that of the superior, aiming particularly at the sides and angle of the jaw*. At the same time, he may emit a characteristic vocalization; rather long drawn out, a squeal rather than a squeak. The entire pattern is not always performed: sometimes the head is merely extended towards the superior and the appeasement squeal is made: sometimes the rest of the pattern is performed without the squeal. It is, of course, possible that when no sound was audible to me, an ultrasonic cry was actually made, for the squeal certainly contains components right at the upper limit of my hearing range.

Appeasement is normally used by an inferior to prevent or to stop an attack by a superior. In halting an attack that has actually started, the mouth contact appears to be the most important factor. If the inferior succeeds in making this contact, the attack is almost always halted abruptly. The superior may then twist and turn his head; attempting to break the contact and if he succeeds, he may attack again, although usually with reduced intensity. In the reared up paws-on posture, it is not uncommon for the pair to stand mouth to mouth. Here the same factor of mouth contact may be preventing either from attacking. I have seen a pair of animals end up in this posture when the original attacker reared to try to escape the mouth contact of the appeaser but failed to do so, since the latter reared with her.

The most dramatic case of an attack being halted by the mouth contact occurred during the incident already mentioned, when a larger male, in knocking a smaller one off the fence, fell with him and the two became involved in a rolling and wrestling fight. This went on for only a few seconds and then-as though a film

*In this sense 'A appeases B' means that animal A addresses appeasement behaviour towards $B$, whether or not it actually has the appropriate effect. had suddenly been stopped, all movement ceased. The larger rat was on top and the smaller had raised his head and established mouth to mouth contact. They remained thus immobilized for $3 \mathrm{~s}$, then the inferior suddenly writhed free and fled.

Appeasement may, however, be used in two other contexts. Firstly, an inferior if he has to pass close to a superior, may detour towards him and appease, even though the superior has given no indication of hostile intent. A very clear example of this occurred when the top male was sitting in the tree eating a nut on a branch a little above a horizontally placed stick leading to the place where I used to offer nuts. An inferior male, having been given a nut, on his return ran up the branch slightly and appeased the top ranker before continuing back down the branch as he had come up (Fig. 4).

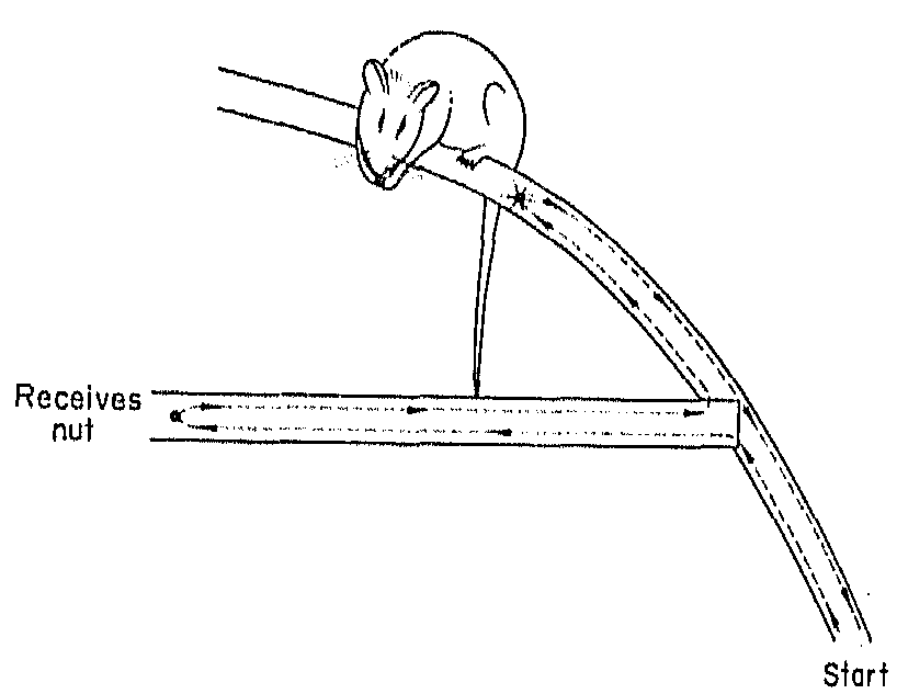

Fig. 4. Appeasement to ensure free passage. Dotted line, path of inferior to and from the nut supply; asterisk, point at which he appeased to the superior (eating a nut) before returning down the branch as he had come.

Secondly, appeasement may be performed with no visible immediate cause, apparently simply with the function of reaffirming the relative social positions of the two animals. A juvenile may approach an adult and appease, and twice I saw a female, after making an attack on a first or second ranking male, return to him a few moments later and appease. One of the attacks was clearly made in error and on the 
second occasion the female had just carried out several chases and was in a highly excited condition. The subsequent appeasement served to re-establish the normal relationship in which she is subordinate to the high ranking male, despite having momentarily behaved in a manner not in keeping with her position.

Table 8. Distribution and Functional Contexts to Appeasement Incidents

\begin{tabular}{lccc}
\hline & $\begin{array}{c}\text { Male } \\
\text { appeased by* }\end{array}$ & $\begin{array}{c}\text { Female } \\
\text { appeased by* }\end{array}$ & $\begin{array}{c}\text { Sub-adult } \\
\text { appeased by* }\end{array}$ \\
\hline Immature & 5 & 9 & 1 \\
Male & 24 & 8 & 0 \\
Female & 7 & 5 & 0 \\
& 36 & 22 & 1 \\
To stop attack & 36 & \\
To obtain free passage & 10 & \\
To reaffirm status & 9 & \\
Mixed & 4 & \\
Total & 59 & \\
\end{tabular}

*See footnote on p. 152.

Table 8 shows fifty-nine appeasement incidents classified first according to the category of appeaser and appeased and then according to functional context. It is clear that the primary use of appeasement is to protect against attack, in particular attacks by males on males. In nineteen of the thirty-six cases of appeasement to a male, the appeased animal was the current top ranker. Since attacks by him are potentially the most dangerous and since all others are his inferiors, it is not surprising that he should be the individual to whom appeasement is most frequently directed. As a result, his status is secured without having to make serious attacks on subordinates.

It still remains to consider what may be the evolutionary origin of the appeasement behaviour and why the mouth to mouth contact should be so effective in staving off attack. Watching a smaller rat pushing its snout against the corner of a larger animal's mouth, one is struck by the similarity to the greeting ceremony of Lycaon and other canids. I do not consider that this is a chance resemblance. Lycaon greeting is simply derivable from the juvenile food begging pattern Kühme (1965). Rats, of course, do not disgorge food for their young but the young nuzzle at the mother's lips and lick her saliva. It therefore seems likely that mouth to mouth appeasement is derived from this infantile behaviour. Its function may originally have been simply to stave off attacks from the mother, at the stage where her maternal responses have been transferred to a new litter of young. In its evolved form, carried over into later life, the appeasement is not only nonaggressive, it implies an infantile status and puts the superior in a position where parental rather than aggressive responses are appropriate.

\section{Injuries}

Despite the frequency of hostilities, severe wounding was not common. The actual process of biting. was seen only four times. Twice bites were delivered on the flank or rump of a fleeing animal: once a female happened to come upon the sub-adult male whom she had singled out for harrying as he sat eating; she promptly bit his tail. The fourth case related to the crippled female, Shan. She was set upon by another female, knocked over and bitten on the flank as she attempted to escape. Had my arrival not disturbed the attacker, she might well have been killed.

A fatal fight was not seen but during the period of study two rats were found dead, apparently as the result of wounds. Both were adult females. One was bitten deeply in the lumbar region and also on the tail, the other on the back, shoulder and flank.

Bites on the tail were by far the commonest type of injury. Apart from these, only fourteen wounds were recorded among the home rats during the whole period of study: six were on back, shoulder or side, three on the nose, three on fore or hind paws and two on the ears. 


\section{Scent Marking and Responses to Smells}

In a species where smell appears to be more important than sight in individual recognition, it is only to be expected that smell should also play a part in recognition of the home area and that some form of marking should be practised. Smell marking was seen, but not very frequently. This is probably because the observations were made during the feeding period and marking may well have been done more regularly later on in the night. Adults of both sexes marked but juveniles were never seen to do so.

Marking is done by rubbing the body against the object to be marked; most frequently a tree branch. There are no highly specialized glandular areas and the rubbing may be done with virtually any part of the ventral surface, from throat and sternal area back to the anogenital region and also with the cheeks. Only eighteen certain instances of marking were seen in the freeliving population and it was not possible to detect any regularities governing the use of the different areas of the body. Both the successful male intruder who took over leadership of the home group and another male who made an unsuccessful effort to force his way in were seen to mark on the home tree. Marking also occurred rather frequently in enclosure III which, although it was part of the territory of the home rats, was less easily defended and more subject to intrusions than the area round the home tree. The circumstances in which the eighteen markings occurred were distributed as follows:

Following ejection of intruder

(two by males and two by females)

Associated with fights or the presence of intruders

Associated with a sudden scare

No obvious immediate cause

Total

The factor common to all cases except the last six is disturbance of one form or another. This suggests that a major function of marking is to announce the re-establishment of the safety of the home area. If this is threatened, renewed marking follows. Of the six markings without obvious immediate cause, two consisted of extensive marking in trees carried out on consecutive nights by the top male. Possibly he may mark as a normal routine at some period during the night.

One curious incident occurred amongst the caged animals. A litter of juveniles and an adult male were removed from the cage one morning; leaving a juvenile, a sub-adult female, an adult male and a female with a week old litter. When these animals emerged at dusk their behaviour was abnormal. The male indulged in a frenzy of marking, rubbing the sides of his face, chin, throat and ano-genital region on the branches. Marking was interspersed with brief bouts of toilet behaviour. He then attacked the sub-adult female viciously, a thing he had not done before. The adult female then emerged. She attacked the younger female, then fought with the male and she also marked with cheeks, chin, throat and ano-genital region. On the following two nights the animals were decreasingly belligerent although still slightly disturbed and the male again marked. It seems most likely that this disturbed behaviour was caused by the removal of the adult male, since one would hardly expect the disappearance of juveniles to have such an effect. I concluded that the missing male must have been the top ranking animal and that his disappearance and the absence of his smell had caused a disruption in the normal social relations. It has already been suggested that the top ranking male may regularly place his marks around the home territory. The presence of his marks, quite apart from any effect it may have on intruders, may play some socially cohesive role, possibly by limiting aggression within the group.

A few tests of the responses of the freeliving animals to foreign odours were made. On five occasions I rubbed the palm of my hand 
across a pathway down the tree or on a stone often used as a sitting place. The rats showed great individual variation in their responses to such marks, some merely sniffing at them, some refusing to cross them and some fleeing all the way back to the roof. Males reacted more strongly than females or juveniles and the rats that fled to the roof were all males. Using a rating ranging from one ( $=$ sniff and pause but no retreat) to four (= flee right to the roof), twenty female and juvenile responses gave a mean score of 1.7 while eight male responses had a mean of 3.0 . Oddly enough, the rats were undisturbed when the anal gland secretion of a long-nosed mongoose (Crossarchus obscurus) was rubbed on a branch: although they detected it, they merely sniffed it thoroughly and passed on. Moreover, they did not appear to detect the smell of human female urine.

\section{Amicable Behaviour}

Apart from the interactions between mother and nestling young, by far the commonest friendly activity is social grooming and the areas most frequently groomed are the face and neck. A male often grooms a female during courtship but may also do so independently of any sexual context. Data on grooming are summarized in Table 9. From these it is clear that although homosexual grooming does occur both between males and between females, grooming is mainly heterosexual, with male grooming female predominating, even when courtship grooming is excluded.

Walking over, as described by Barnett (1958) was seen, but only rarely: it may, of course, occur more frequently in and around the nest area. Crawling under was not seen, but another form of amicable behaviour occurred occasionally. When the animals were resting in the branches of the tree, one rat would shift position so as to sit with its body in contact with that of a fellow. Such contact sitting might involve animals of like or of opposite sex and it was often followed by grooming.

\section{Courtship and Mating}

Complete sequences of mating behaviour were seen only in the caged animals. These conform in general with what has been described by Barnett in Rattus norvegicus and will be briefly summarized before dealing with the more complex events in the free living population.

Mating preliminaries begin with the male following closely behind the female and attempting to nuzzle and lick at her vulva. He may try to pull up her hindquarters with his paws in order to facilitate this. As has already been described, the female at first resists and walks away or may turn and box him off or kick him away with her foot while he attempts to groom her about the face and ears. Finally the female becomes receptive, runs a short distance and then stops. The male follows and mounts, clasping the female's pelvic region with his fore limbs. The female adopts the mating position, with her hindquarters raised and her head extended upwards in the same way as has been described in Peromyscus by Clemens (1969). Mounting is very brief and the male then springs off, rises on his haunches and licks his penis. If the mounting lasts for over a second. the female usually gives a soft squeal, which

Table 9. Social Grooming

No. of occasions seen

Male grooms male

Female grooms female

Non-courting male grooms female

Courting male grooms female

Female grooms non-courting male $\left.\begin{array}{l}2 \\ 6\end{array}\right\}$ Total homosexual grooming occurrences

8

$\left.\begin{array}{r}18 \\ 13\end{array}\right\}$ Total heterosexual grooming occurrences 40 
presumably indicates that intromission has occurred: she also sometimes licks her genitalia after the male has dismounted. The whole sequence is repeated a number of times. The female again runs off and pauses. If the male does not follow, she may stand for a moment with her tail vibrating rapidly, then run on and again pause, or she may herself take the initiative: moving over to the male, she pushes against him and she may groom his head briefly or sniff his genitalia before running off and once more pausing. If more than one male is present, they may all follow the female in a line, one behind the other. Following of the female is sometimes interrupted briefly while one male chases off the others but this does not often happen. In the cage, bouts of mating activity usually lasted for about $10 \mathrm{~min}$ and were followed by a rest period of roughly the same duration before activity was again resumed.

In the free living population the entire sequence from the first following of the female by a male to the achieving of intromission was never seen in one and the same mating. Either the preliminaries had already taken place on the roof before the animals appeared in the tree or on the ground or else they retired to the roof before the mating was completed. All stages were, however, seen a number of times on different occasions. Out of a total of thirty female heats, only the early stages of following were seen in fifteen instances, mountings were observed in eleven and in the remaining four the female was receptive and about to accept the male when some disturbance interrupted the sequence. In a very few cases the female turned and bit at the male as he dismounted, an action not seen in the cage.

In the space available to the free living animals, it was noticeable that the female when ready to accept the male, did not usually move directly away from him but instead more often ran in a circle. This reduced the chance of the partners becoming separated but even so, it was not unusual for a male to lose track of the female and sometimes a second male would then start to follow her. Only once, however, were two males seen simultaneously following a female, one behind the other, as happened very frequently with the caged animals. The reason for this difference seems to lie in the male dominance relations characteristic of the free living population. A high ranking male would always displace a subordinate if he encountered him following a female. The subordinate usually fled at the first hostile move. If the reverse happened and a subordinate came on a superior male already following a female, he would withdraw at once. This did not, however, result in the top male having a monopoly of the females. Of the eleven matings seen, only three were by the top ranker: seven were by large males and only once was a small male seen copulating. He was, however, very soon chased away by the second ranking male. The late rising habits of established top ranking males have already been mentioned and many of the matings by males other than the top ranker occurred when the latter was nowhere to be seen. In other instances, however, the top male had displaced a subordinate and pursued him when he fled and as a result he lost track of the female. A third male was then able to seize the opportunity to mate with her.

Two instances of the female apparently exercising a choice and refusing one male in favour of another were seen.

\section{Ambivalent and Displacement Behaviour}

Actions conforming to the classical descriptions of ambivalent and displacement behaviour were seen on a number of occasions. Recent work shows that these concepts are less simple than was at one time thought, and a full treatment may be found in Hinde (1970). Here, the terms are used merely as convenient descriptive terms. In the category of ambivalent behaviour comes what I have called 'circling', although the animal usually runs in an ellipse some two or three times its own body length in major diameter, towards and away from some object which it is simultaneously motivated to approach and to 
avoid. On two occasions, an intruding male, who had previously been raiding at the feeding place circled towards and away from the food as soon as the top ranking home male had come down and started to feed. Another rat belonging to the home group twice circled between the tree and the food, apparently in indecision as to whether to go up the tree or return for a little more to eat. Circling was also seen when Scarface, the female intruder who succeeded in making her way into the home group, was attacking a number of home rats on their own ground. Several times, however, she failed to carry an attack home and circled towards and away from her opponent. Circling was also seen four times when a home rat had chased an intruder as far as the territorial boundary. This was particularly likely to happen, as in the following incident, when the chase went along the veranda instead of stopping at the wire netting fence.

A home female chases an intruding female down the veranda. A little beyond the boundary the latter stops running and stands. The home female continues to run but turns as she does so and heads back towards home: she pauses, her tail vibrates slightly and she turns again towards the intruder and then continues to circle without further pausing, four times in all before finally returning home.

The fact that a receptive female usually runs in a circle, away from and then back towards the male, is a special case of ambivalent circling which can be regarded as having become a regular component of the mating pattern. Circling was seen twice when a highly excited rat had chased off an intruder. This could be regarded as displacement behaviour, arising from thwarting of attacking tendencies by the disappearance of the opponent. It is not strictly comparable with the case quoted above, since it did not take place at the territorial limit. Moreover, in the same situation circling may be accompanied by a number of other actions which have the appearance of displacement behaviour, such as vibration of the tail, isolated toilet actions, scraping the ground with the fore paws and sometimes pushing with the hind feet also, as in digging. When such behaviour occurred the rat was always in a highly excited condition and the notes made at the time always contain words such as 'violent' or 'frenzied'. The opponent may sometimes have vanished simply because the pursuer lost track but more often the attacked rat was an intruder who fled out of the home territory and the attacker turned back at the boundary. That the home rat does turn back, even if this causes thwarting sufficient to produce displacement behaviour is a demonstration of how strong is the tendency not to pursue beyond the limits of the territory.

Tail vibration has already been mentioned as occurring now and then during mating activities but it is not an essential part of the sequence and is not regularly performed. The other situations in which it was seen suggest that it is simply an expression of a high level of excitement whose outlet is temporarily blockedin mating by a delay before being mounted. There was never any indication that it served as a signal. In mating the pauses made by the male between mounts were determined by how long his attention was concentrated on licking his penis and he never gave any sign of being influenced by the vibration of the female's tail. Similarly, in hostile situations, I never saw anything to suggest that tail vibration functioned as a threat.

Face washing was also seen now and then, when an animal was hesitant about venturing along the narrow stick that led to the supply of groundnuts or if it dropped a large piece of food while trying to carry it up the tree. It was also common for a rat that had just chased out a raider to go to the water dish and take a brief drink. This happened so often that it seemed difficult to believe that a displacement component was not involved. In Rattus norvegicus, Barnett (1958) saw grooming and digging occur as displacement behaviour, together with two other actions, gnawing and eating, which I did 
not see in the displacement repertoire of $R$. rattus.

\section{E. Reproduction, Parental Care, Development of Young}

Observations on the rearing and development of the young were made on animals kept in the large cage in the laboratory. Even animals born in the cage remained extremely shy and easily scared and females with litters blocked up the observation windows of the nest boxes so effectively that behaviour inside the nest could not be watched without major disturbance. Four young, two males and two females, were therefore hand reared from just before the eyes opened and when weaned were put in the smaller double-unit $2 \times 0.3 \times 0.3 \mathrm{~m}$ cage, where observation of the nest boxes was easier. Even these animals, however, were by no means tame. They showed no fear of me and would readily contact my hand but any movement or noise evoked all the normal flight behaviour typical of wild animals. Eibl-Eibesfeldt (1953) also remarks on the extreme shyness of Rattus rattus and he too found that hand reared animals were never fully tame.

Thirteen litters in all were born to females kept in the cages. Gestation periods for first litters were 21 or 22 days while for litters born to already lactating females they ranged from 23 to 29 days. Since simultaneous lactation is known to cause delayed implantation in Rattus, this variation is to be expected (Mantalenakis \& Ketchel 1966). Females had their first litters at ages ranging from 95 to 143 days. A post-partum oestrus normally followed within $24 \mathrm{hr}$ of parturition. Litters were therefore born at intervals of a little less than a month: one female, for example, successfully reared three litters separated by intervals of 25 and 29 days.

Eight was the commonest litter number and ten the highest. The lowest recorded was three but since the birth was not witnessed, the number born may have been higher and some young may have died or been killed and eaten.

Dieterlen (1963) gives gestation periods rang- ing from 20 to 24 days with litter numbers of 6 to 20: Storer \& Davis (1953) give $7 \cdot 3$ as the mean number of embryos per pregnant female for $R$. rattus in San Francisco but do not give the range covered.

The young are completely unpigmented at birth and the tail is relatively short, approximately a third of the body length. In the adult the tail is longer than the body and its importance in climbing has already been mentioned. The giant rat, Cricetomys gambianus, also also has a long tail which is used in climbing. In a previous study (Ewer 1967) it was found that the tail in young Cricetomys grows extremely rapidly just before the young are ready to start foraging, so that the adult proportions are attained by the time the juvenile makes its first climbing excursions. It therefore seemed of interest to find out whether Rattus rattus has a similar acceleration of tail growth in the im. mediate pre-emergence period and also whether it differs in this respect from the more terrestrial $R$. norvegicus. Measurements of body length and tail length were therefore made on three $R$. rattus litters and, for comparison, on two litters of white laboratory $R$. norvegicus. The results are shown in Figs 5 and 6 . It is clear that tail growth is indeed very rapid in $R$. rattus and the tail is already slightly longer than the body by the time the young first emerge from the nest at approximately 3 weeks old. Figure 7 shows the length increments in successive 5-day periods, read off from the smoothed curves of Figs 5 and 6. $R$. rattus shows a sharp peak at around 15 days, whereas in $R$. norvegicus the peak is both smaller and later. The data are therefore in accord with the idea that for the arboreal species it is important that the tail attain the adult proportions before climbing starts, whereas for the more terrestrial species there is no such urgency.

The developmental stages reached at different ages during the nestling period are summarized below:

Age (days)

2 Dark pigment appears on head 


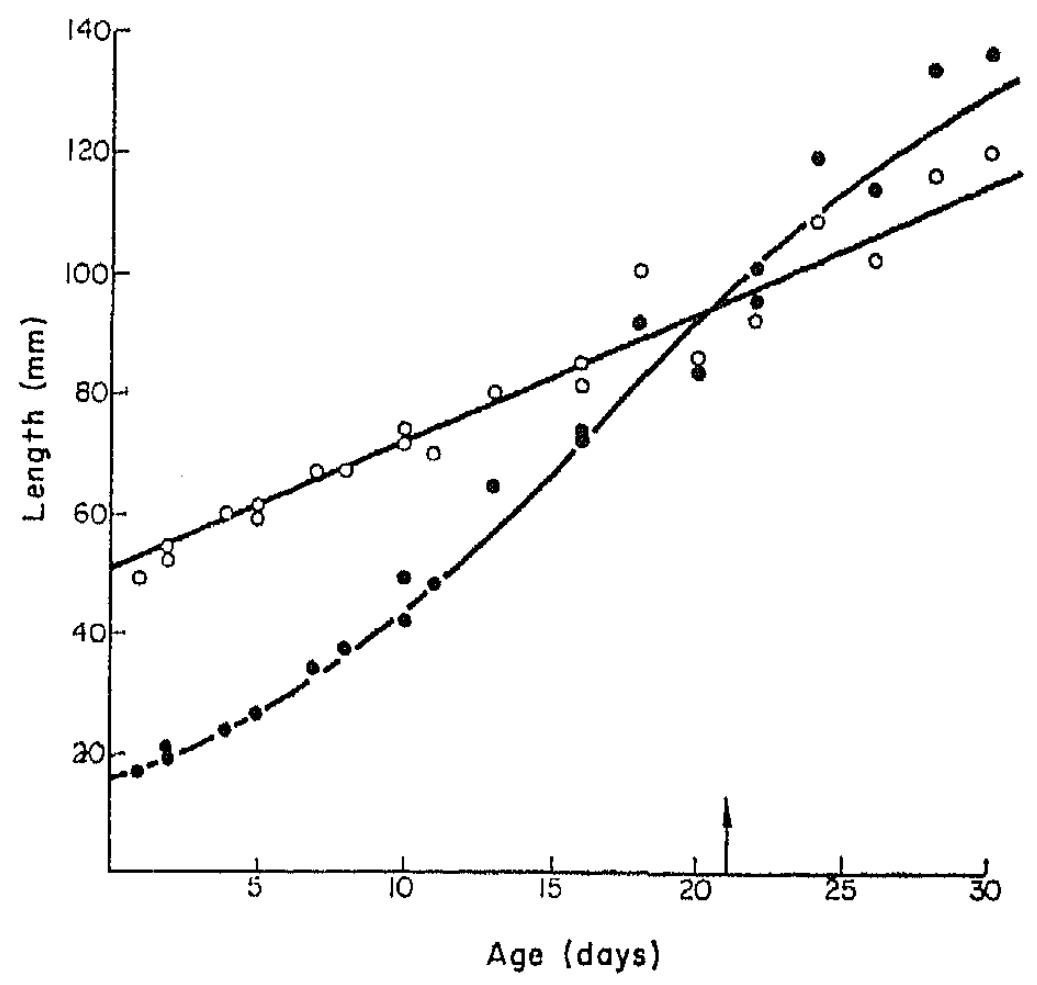

Fig. 5. Rattus rattus: length of body (open circles) and of tail (filled circles) at different ages. Data from three litters; each point is the mean for a single litter; arrow shows normal age of emergence from nest.

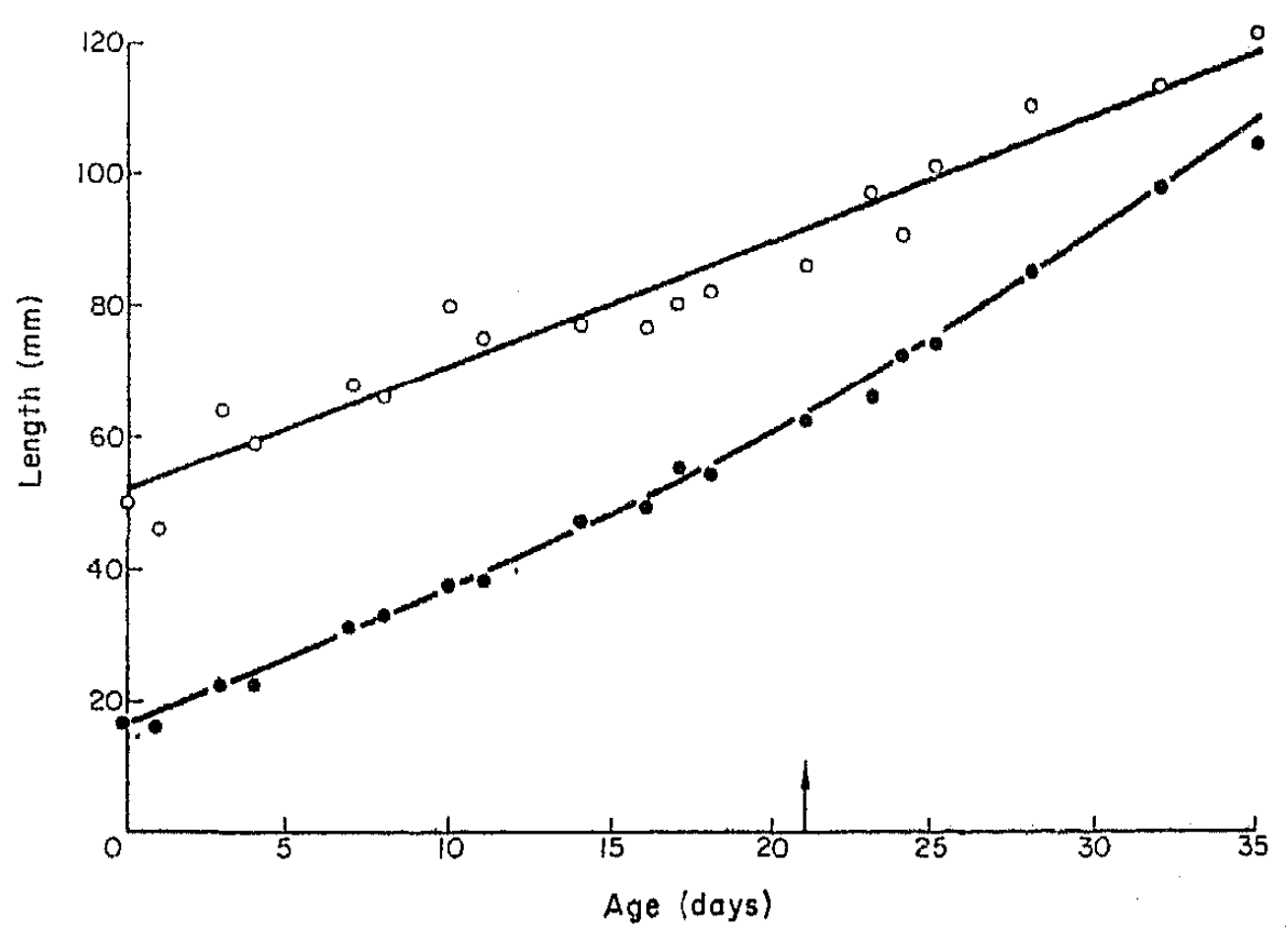

Fig. 6. Rattus norvegicus: length of tail. Conventions as in Fig. 5. Data from two litters. 


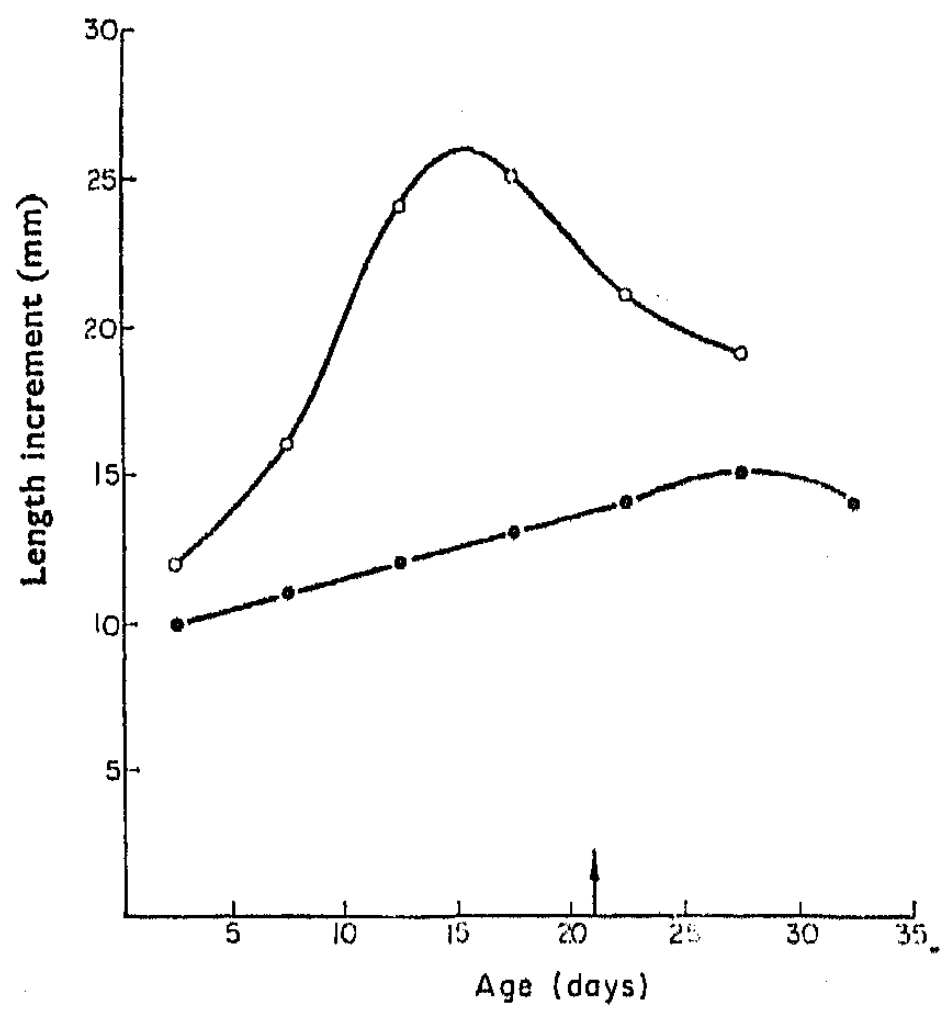

Fig. 7. Length increments of tails over 5-day periods, calculated from the curves of Figs 5 and 6 . Open circles, $R$. rattus; filled circles, $R$, norvegicus.

$5 \quad$ Fully pigmented except on upper arm

7 Faint down of hair on head and shoulders Audible distress squeak in response to handling

8 Fine fur all over.

10 Teats clearly visible in female but much less obvious in male. (A little later hair growth conceals the teats: 10 days is therefore the age at which it is easiest to determine the sex of the young.)

10-16 Eyes open. Clinging response and 'edge response' (see below) appear.

15-18 Start nibbling at solid food. Very active inside nest.

17-23 First explorations outside the nest and within a few days playing starts.

The young do not usually emerge voluntarily from the nest before the age of about 3 weeks. They may, however, stray out accidentally or be dragged out clinging to the mother's teats at a slightly earlier stage. For a terrestrial animal an accident of this sort is not likely to be serious but for an arboreal species it could be very hazardous. The clinging response and the edge response which mature during the second week of life serve to minimize the danger of the young falling to the ground. The young are at first easily handled and remain more or less passive when picked up. When the clinging response appears, however, one suddenly finds that they cling firmly to one's fingers and do so with such efficiency that it becomes quite difficult to get them off one's hand and into a container for weighing. The value of this tendency to cling is obvious and the 'edge response' is complementary to it. This latter consists of a withdrawal from any declivity whose bottom is out of reach of the vibrissae. It can easily be demonstrated by placing a youngster on top of a large book laid flat on a bench. The animal will move about until it comes to the edge, sniff and whisker over the declivity and then retreat. The eight young of a litter were tested in this way at the age of 13 clays, three consecutive withdrawals being taken as a positive $\left(t^{-}\right)$edge response. One refused to move, one managed to reach over far enough to contact the ground with its vibrissae and crawled down, the other six gave a very clear positive response. $R$. norvegicus also shows an edge response but the clinging response is very poorly developed.

During the nestling period the female becomes more active in carrying food to the nest and may accumulate a considerable store. Her habit of blocking the entrance to the nest has already been mentioned. The female in the small cage always covered her young completely before leaving the nest. When disturbed in the nest in the lower cage, she moved the entire litter to the upper cage, carrying them very expertly by the skin near the centre of the back. When they first started to make their way out of the nest at 19 days old, she spent some time in fruitless efforts to carry them all in again but presently abandoned the effort and was not seen to retrieve again. In laboratory white $R$. norvegicus there is considerable improvement with experience in the female's ability to pick up a pup so that its weight is correctly balanced (Carlier \& Noirot 1965). Comparable studies on 
$R$. rattus would be of interest, since clumsiness at retrieving is likely to be more heavily penalized in an arboreal species and this particular female appeared to be extremely adept without requiring practice.

At about the time the young are leaving the nest, they show two new reactions towards the mother. The first of these is saliva licking. They sniff around the mother's mouth, particularly at the corners and lick at her lips. This behaviour was seen both inside and outside the nest. Sometimes the young started to lick when the mother was cleaning her face and paws: presumably they were attracted by the smell of her saliva. In all cases the initiative came from the young and the mother was tolerant, rather than actively co-operative or encouraging. On two occasions an infant was seen attempting to lick the mouth of a male. He did not repulse it but tried to move his head out of reach. Licking was also seen a few times amongst the free living population. The second response consists of approaching the adult and climbing on her back. The female usually took no notice of the youngster and it soon desisted. I did not see attempts to climb on a male but one youngster in the free living population did climb on two females in succession, so the response is not always restricted to the mother. Its significance remains obscure.

Leading of the young was never seen and although the young would often follow an adult for a short distance, in the free living population they always made their first trips down to the feeding place without any parental assistance. Since she will normally be rearing another litter very shortly after the current young have left the nest, it is not surprising that the female very soon ceases to show any interest in her postnestling young. The immunity of the young from attack at the feeding place has already been mentioned but whether this immunity also holds near the nest is not known for the free living animals. A female is, however, normally very aggressive near a nest containing a litter and it is possible that even young in their early post-nestling stage may be in danger of attack near the nest. The behaviour of one of the caged females was of interest in this connection. She was rearing a litter and had become very hostile to the young of the previous litter. On the evening when her current litter first emerged from the nest at 22 days old, her behaviour had undergone an abrupt change. The juveniles were no longer attacked even when they approached the nest box. This sudden decline in aggressiveness may be correlated with the emergence of the younger litter and would serve to prevent attacks being made on them in error. A female Cricetomys gambiamus showed an exactly comparable sudden change in mood. She had become very aggressive during the rearing of a litter but her hostility vanished suddenly between the mornings of the 22nd and 23 rd days. At the time I did not notice the correlation with the development of the young but in fact they made their first excursions out of the nest on the evening of the 22nd day. In both species it thus seems that as a protection to the emerging young, there may be a sudden switching off at the appropriate time of the tendency to attack anything moving near the nest.

In the early post-nestling stage, the young go through a period when they are extremely playful. The two common forms of play are fighting play with a littermate and locomotor play. The main type of locomotor play is running hither and thither, usually as an individual activity although now and then one youngster may chase another: it also includes making little vertical leaps in the air, exactly like the 'hop-skip' described in Cricetomys (Ewer 1967). Boxing and wrestling are the common types of fighting play, often interspersed with a hop-skip; broadsiding appears more rarely. Sometimes if one partner moves away, the other may continue for a few moments jumping around, as though still playing with an invisible companion. Sometimes an infant will play fight with the mother, boxing at her nose or attacking her moving tail. Older juveniles also sometimes become involved in play with the infants and the father 
of the small cage litter sometimes joined in. He boxed with them very gently and now and then would break off and run to the far end of the cage and back again with the young sometimes chasing after him when he did so. In the cages the infants normally played shortly after emerging from the nest in the evening and before they went in search of food. In the free living group play between small juveniles was sometimes seen in progress in the tree top but it probably occurred more frequently on the roof of the veranda. On one evening when $I$ watched from the roof a group of six infants who had made their first appearance at the feeding place a few days previously were together on the veranda roof in the shelter of the overhanging tree branches. They played for 20 min before any of them came down the tree to the feeding place.

After a few weeks play ceases to be an important activity but even adults may play occasionally and thus one cannot say that there is a definite age at which play ceases. Moreover, serious fighting does not first appear when sexual maturity is reached but develops gradually out of playful fighting. Small young fight only playfully but juveniles may do so seriously and amongst the smaller juveniles there are often 'transitional fights' which do not fall clearly into either category or which oscillate from one to the other. Poole (1967) has described the same sort of progression from playful to earnest fighting in young polecats and transitional fights are also very common in young civet cats (Civetta civettictis). Possibly a transition of this sort is typical of species in which intra-specific fighting is common amongst adults.

\section{F. Problem Solving}

Three simple tests were made of the ability of the free living rats to reach food placed in unorthodox situations.

\section{String Pulling}

Ground nuts were impaled on pieces of bent wire and suspended by strings from a narrow branch or from the horizontal wire already mentioned. This presented no difficulty to the rats: it normally took them no more than two trials to find out how to pull the string up hand. over-hand and reach the nut. The reason for this surprisingly fast finding of the correct solution was clearly apparent. On first becoming aware of the nut by smelling it, the rat would lean over and try to reach directly down to it. The string, however, was too long and after nearly overbalancing the rat would draw back to a stable sitting position on the branch and try again more cautiously. This time its paws would contact the string and the rat would attempt to walk down. Before reaching the nut, it would again reach the point where it was in danger of overbalancing. Its hindquarters would remain poised over the branch and could not be moved further, but it still tried to go on walking down the string with its fore paws. The result, of course, was to 'walk the string up' and in a moment the nut was within reach and was seized in the mouth. At the next trial this technique was adopted without hesitation. At first the pulling up was rather clumsy and the movement of the fore limbs was clearly the locomotory one, involving protraction and retraction of the limb but not a great deal of flexion at the elbow. With experience this was soon modified into a genuine pulling up movement involving more flexion at elbow and wrist and the rats became extremely adept at string pulling (Plate II, facing p. 141).

There was nothing to suggest that any rat learnt how to pull up a string by seeing another rat do so but the presence of one animal eating on the nut branch did accelerate learning by its fellows, by virtue of the fact that they were alerted to the presence of food in a new place. The location of the strings was quickly learnt and rats would run to the nut branch and pull up all the strings, even if they bore no nuts. They did not work systematically and might pull up the same string several times: indeed, having eaten the nut off the end of a string, a rat would often promptly pull up the same string again and sniff the empty hook. If a 
string was removed, the rats would feel for it in the accustomed place. Once when a string had been removed, a rat, searching for it in the normal place on the wire and failing to find it, reached back a little further than usual in his efforts and touched his own tail, hanging down on the other side of the wire. He pulled this up in the normal way, dropped the nutless end when he reached it, paused a moment and then repeated the whole process once more before giving up and running off.

\section{The Puzzle Box}

The puzzle box consisted of a cylinder of wire netting, $12 \mathrm{~cm}$ high and $8 \mathrm{~cm}$ in diamter, nailed in an upright position to a horizontal wooden base with a handful of ground nuts placed inside. The easiest way for a rat to get a nut out of the puzzle box was to jump on the upper edge, reach down inside the cylinder and pick up the nut in the normal way in its mouth. In the event only a minority of the rats succeeded in mastering this technique: the majority reached in through the wire at the bottom and with considerable difficulty scraped out a nut with one paw. This was not easy, since the mesh restricted their arm movements and they never became very skilled at pulling the nuts out-very often their efforts would merely push a nut further away, instead of drawing it nearer. Two factors made it hard for the animals to discover the simpler and more efficient route over the top. Firstly, the rat detects the nuts by smell and can bring its nose virtually into contact with them through the wire. To go over the top necessitated an initial withdrawal from the goal and most rats were incapable of doing this. Secondly, since they did succeed in scraping out the nuts through the wire, even if some effort was required, their 'wrong' solution to the problem was rewarded and this tended to make them persist in it. When the bottom of the cylinder was closed off by a few rounds of sticky tape, so that the nuts could no longer be reached in this manner, then the route over the top was very quickly discovered. When the tape was subsequently removed, those rats that had learnt the quick method continued to use it.

Very striking with the puzzle box was the total failure of one rat to learn from another. Time and again a rat might be scraping ineffectually at the base of the cylinder while another repeatedly took nuts by the upper route literally from before its nose: the scraping animal merely scraped more frantically. The second rat might even push the first aside, in order to jump on the edge of the puzzle box but still the first did not 'see' the solution; apparently because the olfactory stimuli from the nut remained the dominant element in the situation. First solutions seemed to be largely a matter of chance and young rats, being more agile, were the ones most likely to find the route over the top. Often they first jumped on the edge of the wire because one or more adults were blocking the direct approach below. One particularly aggressive female found the way in by what was very obviously a lucky chance. She had been driving other rats away from the nuts and in the course of doing so, she happened to jump on top of the wire. She suddenly found that the nuts were now directly accessible just below her and reached down and collected a nut. As it happened, this was the last nut, so she could not repeat her performance and get any more. I therefore waited with some interest to see what would happen on the following night when the puzzle box was again loaded with nuts. She went straight in over the top and thereafter always used this method. Judging from the performance of the rats with the empty strings, it is very likely that during the course of the night she had jumped on the edge and searched the empty box several times, but the fact remains that the single rewarded performance was sufficient for her to learn the more efficient method.

\section{Fishing}

Black rats are not known to search for food in water but towards the end of the study period I put a few nuts in the drinking dish, the depth 
of water being about $3 \mathrm{~cm}$. Rather to my surprise, the first rat that came to drink, a young male, at once noticed the nuts, apparently by smell rather than by sight. He first tried to pick them up in the normal way in his mouth but was unwilling to put his head into the water far enough to reach them. He then tried scraping with his paws and in the end succeeded in getting a nut. He soon became very adept at this and would perch on the edge of the dish and rake the water with both fore paws simultaneously. When a nut was located, he picked it up between the two paws and took it into his mouth. Sometimes he would walk right into the dish and stand in the water as he raked. Occasionally he even sat up on his haunches in the water and ate a nut. The process of finding the nut appeared to be entirely tactile and he never looked what he was doing as he fished.

Very soon this particular rat learnt to go at once to the water dish and fish out the nuts. He then began to chase away other rats that approached the dish. Normally although the rats, especially the most aggressive females, might chase others away from the feeding place, there was never any squabbling between group members at the water dish and two or more rats would drink together side by side. Clearly for the fishing rat, the water dish had been transformed into a feeding place. As a result both of his skill in removing all the nuts and of his tendency to drive off others, it was some time before any other rat learnt to fish. A grey juvenile, however, managed to do so and was allowed to share the nuts. $\mathrm{He}$ and the larger male would fish together, the juvenile now and then pausing to put his mouth to the other's in

\section{the appeasement gesture.}

From these tests three things were apparent. Firstly, that insight played no part in solving the problems posed. The rats simply attempted to get the food by the most direct method, using their normal behaviour patterns. Once a success was achieved, however, even if this was more or less by chance, they were extremely quick to learn what to do. They learn, in fact, not by trial and error but by trial and success. Secondly, once a successful method had been found, they were quick to improve their technique, even if this involved something unorthodox. The string pulling movement, although developed from the walking pattern, is not a part of the normal repertoire and no rat normally picks up food with its paws, as the fishing rats learnt to do. Finally, the only thing the rats learnt from each other was that food was to be had at a certain location: the details of how to get it each had to discover for itself.

Tests of observational learning have not always distinguished between these two sorts of learning. Mainardi \& Pasquali (1966), for instance, found that 'pupil' mice who had seen a 'teacher' solve a problem themselves solved it faster than controls. The problem was to push aside a hanging door, so as to pass through a hole in a partition to reach food. The results, however, do not show that there was insightful learning. On the contrary, the long times involved strong: ly suggest that what the pupils had learnt was that it was possible to get through the partition and find food, but that they had to discover for themselves how to achieve this: in fact, they knew what the problem was, not how to solve it. 


\section{DISCUSSION}

The first point which requires consideration is the type of environment in which the present observations were made. The situation was natural, in that the animals were free and their activities were in no way restrained; but it was unnatural, in that a constant food supply was regularly put out at a certain place. The feeding place, however, is comparable with an urban rubbish dump or domestic garbage heap-a type of food source which rats are quick to exploit. The behaviour seen can therefore be expected to correspond closely with what would be shown in an urban situation, offering ample opportunities for scavenging within easy reach of nesting facilities. This can be regarded as a type of habitat which has become normal for Rattus rattus and one to which the species has become adapted over a period at least of centuries. The behaviour seen should therefore not be particularly distorted as a result of the unnatural features of the environment, although obviously it would also be of interest to have comparable data on behaviour in a nonurban environment.

In their studies of populations of wild Rattus norvegicus in rural villages, Barnett, Bathard \& Spencer (1951) found that dispersal into new areas took place before the central populations had reached their maxima. The present study has shown that in $R$. rattus, too, dispersal occurs before there is any food shortage, as long as the neighbourhood provides areas suitable for colonization. It is the young adults who emigrate and although this is partly the result of the hostility of older members of the group, many of them appear to leave at this age without having been particularly harried. When vacant places become scarcer, restriction of breeding occurs, again before there is any shortage of food. This also is paralleled in other species. A recent study by Terman (1969), for instance, has shown that in laboratory populations of Peromyscus the same thing happens but the density at which breeding success is affected is not identical in different populations kept in identical environments. This, Terman suggests, indicates that the controlling mechanism is not crowding per se but some behavioural changes caused by crowding, which might be expected to show individual variation. The same is probably true of the $R$. rattus group studied and, in view of the successful breeding of the female who nested apart, it appears that the controlling factors operate more stringently in and around the nesting area than at the feeding place.

It is of some interest to compare the present findings with the results obtained from studies made on captive animals, in particular with those of Eibl-Eibesfeldt (1953) and of Barnett (1958). The patterns of behaviour seen are in general agreement but, as is to be expected, there were some differences. Eibl-Eibesfeldt and Barnett \& Spencer (1951), for instance, report a repetitive hissing vocalization, used as a threat, which I never heard from my animals, while Eibl-Eibesfeldt never heard tooth gnashing in $R$. rattus. This difference is almost certainly merely a question of slightly different situations. Gnashing is elicited only in some very specific conditions which I never succeeded in defining and the fact that Eibl-Eibesfeldt never heard his rats gnash is not very surprising: the correct situation may never have arisen. Similarly, although I never heard the hissing threat, it is quite likely that this was also because the appropriate circumstances never arose. The fact that Eibl-Eibesfeldt did not see scent marking by rubbing, while I never saw the marking with urine drip trails which he describes may also be a function of the different environments. A more surprising and less easily explicable difference between his rats and mine relates to feeding habits. Mine were actively predacious and took meat scraps avidly: his were almost entirely vegetarian and refused meat, both raw and cooked. Possibly this difference is correlated with the fact that $R$. norvegicus is not present in 
Ghana. It may be that where there is competition between the two species, $R$. rattus becomes restricted to a more strictly vegetarian regime; or possibly it might be more correct to say that only in the absence of such competition do urban $R$. rattus become carnivorous to any significant degree.

Eibl-Eibesfeldt (1953) says that while fishing behaviour is known to occur in wild $R$. norvegicus, $R$. rattus never behaves in this way and tends to avoid water. My rats very quickly learned to fish in a manner very similar to what he describes for $R$. norvegicus. This difference too may relate to competition between the two species but it could also be no more than a temperature effect. $R$. rattus, being a more tropical species, may be prepared to search for food in water only provided the water is not cold.

When we come to consider social organization, the comparison between free living and captive animals becomes more complex. Studies on caged animals are not a reliable guide to the social organization of free living populations, as has been shown particularly clearly for primates. The social relations may be altered by two factors acting in opposite directions. Constrained close proximity may lead either to an accentuation of aggression or, conversely, the animals may become adapted to each others' presence and come to show tolerance in circumstances which would normally provoke hostility. Barnett (1958) found 'no division by social status' in his caged $R$. rattus colonies, but very definite dominance relations were seen in my free living population, including a hierarchy amongst old males. Barnett (1963) states that in rats there is no behavioural evidence for individual recognition, but this was certainly not the case with my $R$, rattus. When the three old males were present, rat no. 2 in the hierarchy could certainly recognize nos 1 and 3 and a top ranking female could distinguish her fellow top female, the top male and another male whom she selectively harried. These are, of course, minima. The rats may have recognized individually other animals that were indis. tinguishable to me and no particular attention was devoted to trying to discover the upper limits of their faculty of recognition. The dis. crepancies between Barnett's and my findings could easily arise from the differences in living conditions. Barnett's animals were kept in very restricted conditions in cages measuring only $0.6 \times 1 \times 0.6$ or $1 \mathrm{~m}$ and with no furnishings other than three nest boxes. With up to twelve rats present, crowding must have been intense and one could hardly expect a normal social order to develop. Eibl-Eibesfeldt's rats were much less closely confined, some living free in his laboratory and some in a large terrarium. He does not discuss social organization but refers incidentally to a rank order, so presumably there were status differences amongst his animals.

The most surprising difference between Barnett's and my animals, however, relates to the behaviour of the females. In his, 'fighting was a male prerogative' whereas in mine, the females were often very aggressive and were largely responsible for territorial defence. Moreover, the two rats found killed were both adult females: since males were never seen to attack females seriously, they were presumably killed by females. This difference does not seem to be attributable in a simple manner to the difference between the caged and free living environments for with my animals, females were also aggressive when kept in cages: they attacked even their own offspring who had been born and had grown up together with them in the cage and a resident caged female killed a newly introduced female. Amongst Eibl-Eibesfeldt's rats also, females made attacks on introduced aliens. Possibly the discrepancies may be related to how long and in what conditions the animals had been bred in captivity, for Barnett \& Stoddart (1969) have found in $R$. norvegicus a decrease in propensity to attack after a few generations of breeding in captivity, but they are more likely to be a function of the living conditions, for even my caged animals had considerably more 
freedom than Barnett's. Yet another difference between my rats and Barnett's is that he found that littermates reared together did not mate, which was not true of my caged animals. Breeding between littermates took place not only between the hand-reared animals but also between naturally reared rats in the large cage. It is of course also possible that genetic differences between the rats of Glasgow and of Ghana were responsible for some of the differences observed.

In the population $I$ studied, the group had a definite social structure and maintained its integrity despite the fact that its composition was not wholly stable. This integrity is based on the fact that strangers are distinguished from group members and that there is a territory from which the latter are, as far as possible, excluded. It is therefore necessary to consider the nature of the territory and the factors which determine its limits. So far no distinction has been made between one part of the territory and another. There were, however, very definite gradations from the central tree (the main route to the nest area) and the feeding area near its base to the more peripheral regions. The existence of the wire netting fences emphasized these differences. Enclosures II and III, although they 'belonged' to the home group were not defended as effectively as enclosure $I$ and rats from B group could often enter them without being noticed. Similarly the veranda bordering enclosure I was less defended than the area inside the fence and the intruding female, Notch, was often able to make her way round on the veranda to take nuts from me. Within enclosure I itself there was also a gradient. An intruder could sometimes hide in the vegetation towards the periphery but was never permitted to remain in a refuge near the tree. In interactions within the home group too, the same gradation was seen: attacks rarely took place in the periphery and an inferior could often escape by running down the outside of the fence at the edge of the veranda. The superior rat appeared to be simply not motivated suffic- iently to continue a chase in this area. This all reflects the fact that the tree and the feeding place were the most used areas and therefore the ones in which encounters are most likely to occur. The data available are not sufficient to show whether differences in aggressiveness in relation to an individual's spatial position are also involved. It does, however, seem clear that the limits of the territory are set at that point where a defender's attacking tendency is counterbalanced by the tendency not to leave the safety of 'home', as represented by the central tree giving access to the nests.

It is easy to appreciate that the home rat chased by a fellow should be strongly motivated to seek safety and therefore refuse to be driven away from home beyond a certain point. But the turning back of a defender pursuing a fleeing intruder shows that in this situation the tendency not to get too far from base is equally strongly activated. In any agonistic situation, then, whether attacking or escaping, the attraction of 'home' is in operation and the territorial limits are made visible as the turning back point. However, if this were the only factor involved, one would hardly expect such near unanimity as appeared to exist within the group as to where these limits lie: for less aggressive animals one would expect them to lie closer to the tree than for the more aggressive individuals. Two further factors operate, tending to formalize the limits into something approaching a genuine boundary. The first of these is smell marking: this must have the effect of delimiting the area within which group members set their marks quite sharply from the area free of home smell so that it is as though at the boundary 'distance from home' undergoes a sudden increase. Secondly, rats are very competent at learning their way about and are thoroughly familiar with the local topography. It would therefore be extraordinary if learning did not reinforce the tendency to turn back at a certain point and so contribute to delineating a definite boundary. In non-agonistic situations, however, this boundary may cease to have any valency, for the rats 
foraged well beyond the territory. This can only mean that when in a different, exploratory mood, the tendency to stay near the safety of home is in temporary abeyance and the rats are therefore not turned back when they reach the boundary. The fact that foreign males readily entered the home territory when a female was coming into oestrus is another example of the fluctuation of the valency of their own territorial limits in relation to current mood. This linking with mood prevents the territory from becoming a prison: the 'boundary' is not permanent and the rats are free to cross it when the circumstances are appropriate.

The importance of this last point is often neglected in dealing with the territories of small mammals. The territory held by the home group of rats was very small, its longest diameter slightly under $18 \mathrm{~m}$, but there was no need for it to be any larger. It contained the nest area, an adequate feeding and drinking place and the routes linking the two together-all the necessities of rat life. However, if a group of rats knew only a small area of this type, they would be extremely vulnerable. Food sources are not always reliable; many are seasonal, dustbins may acquire lids and even a refuse dump may be converted into something much less useful to a rat; trees can fall down or houses be demolished. The animal that already has some familiarity with the neighbourhood beyond its territory is obviously in a much better position to find a new home than one knowing only his own small territory would be. Moreover, even if there is no disaster, it may happen that conditions somewhere else become more favourable than at the old home. The explorer is free to shift but a stay-at-home would never even become aware of the better area. Emigration too is much more likely to result in successful establishment elsewhere if it is preceded by exploration of a large area outside the home.

Myers \& Poole (1961) found that rabbits also make periodic sorties outside their territory and showed that when better conditions were offered beyond its limits, shifting did occur.
We know very little about how far or how frequently $R$. ratius makes exploratory trips but Pippin (1961) has made some experiments on the ability of the $R$. rattus on Mona Island in the West Indies to find their way home when released at various distances from the point at which they were trapped. A number returned home within a few nights from distances of over 1000 yards but the most remarkable performance was that of a rat removed from its home in the laboratory building to a shed 8700 yards $(=7.9$ $\mathrm{km}$, or nearly 5 miles) distant. The rat was home on the second night after release. This implies familiarity with every large area or else some other homing ability for which there is as yet no satisfactory evidence in rodents.

In my caged $R$. rattus the sequence of events associated with mating was extremely similar to what Barnett describes in $R$. norvegicus but in the free living population there were some differences. Preliminary fighting between the males (see p. 137) was more intense since) foreign males appeared in the home area, presumably attracted by the smell of the oestrus female. During the course of the fighting a number of defeated animals withdrew but it never continued long enough for a single victor to emerge, and there were always several males about when the oestrous female finally made her appearance. As in the cage, fighting ceased once a mating had occurred but following of the female by several males in a line was not norm* ally seen. As already mentioned (p. 156) this appears to be a function of the hierarchical social relations developed in the free situation but not in the cage.

Barnett regards the preliminary fighting as a sort of displacement activity, arising because the males are ready to mate, are activated by the smell of the female, but thwarted because she is not yet receptive and will not permit copulation. This hypothesis, however, does not explain why once one male has mated the rest cease fighting and disperse; they do not attempt to mate and must be no less thwarted than before. The following interpretation of the 
sequence of events seems more plausible.

The female coming into oestrus has two effects on the males, presumably mediated by olfactory stimuli: they are attracted from a distance and they become highly aggressive. The resulting concentration of bellicose males inevitably leads to fighting, but it is fighting of a highly stylized variety in which there is little danger of the loser being seriously wounded. Once the female copulates, some change takes place in her and her effects on the males are altered. She no longer attracts them from a distance and their aggression is no longer aroused to the same extent. Fighting therefore ceases and inferiors are free to disperse.

This arrangement, whatever its causal explanation, has obvious biological significance; it ensures that there is male competition not restricted to the home group but this takes place before mating and thus does not result in interference with mating. The fact that the fighting does not produce a single 'winner' does not, of course, invalidate the suggestion that there is competition between the males. The competition, however, is analogous to an examination where all who achieve a certain standard are granted a pass, rather than with a race where there can be only one winner. Any rat that remains until the end of the fighting has a chance of mating, although he is liable at any moment to be displaced by a superior. It is also worth pointing out that although to describe the males as 'fighting over the female' may have anthropomorphic overtones. it is still true to say that, regardless of what the motives of the contestants may be, their behaviour has the result and the function of deciding which males are to be denied any chance of mating. The rat that is driven away during the preliminary fighting is not in the running for the matings that are to follow.

An explanation of the type outlined, in terms of changes in mood brought about by changing olfactory stimuli, accounts adequately for the sequence of events observed and there is nothing inherently improbable about it. Starting with
Bruce's (1959), classical finding that the smell of a strange male can act as a block to pregnancy in mice, there has been a growing body of evidence that in small rodents the sense of smell is important not only in mediating direct and specific responses to particular olfactory stimuli: in addition there may be more generalized changes in responsiveness, including changes in aggressiveness, or longer term endocrine effects. Ropartz (1968), for instance, has found that previously highly aggressive male mice become totally unaggressive when their olfactory bulbs are removed. Myer \& White (1965) found that rats that previously had readily killed mice were much less likely to do so when the same operation was performed on them. Barnett, Evans \& Stoddart (1968) showed that male $R$. norvegicus housed with females were more prone to attack an introduced foreign male than were solitary males, but whether the smell of the female alone is sufficient to produce this effect has not yet been investigated.

A few of the patterns of behaviour seen in $R$. rattus are of interest from the comparative point of view. Tail vibration is one of these. In many rodents tail vibration acts as a threat, as in the mouse and in a highly ritualized form in porcupines. In others it is used by the male in courtship as in Myoprocta (Morris 1962) or both in courtship and also as a more generalized non-aggression signal as in Thryonomys (Ewer 1969). In order to account for these two conflicting uses of a similar signal, it seems necessary to postulate a primitive condition in which tail vibration had not acquired signal value but occurred in situations where the general level of excitation was high -as would be the case both in hostile encounters and in courtship. It could then have been elaborated independently a number of times either as a threat or as a courtship signal. The situation in $R$. rattus comes very close to this postulated phylogenetic starting point. Tail vibration has no detectable signal value and it occurs in situations associated either with agonistic encounters or with mating. These are, however, situations of 
frustration, rather than of conflict. In agonistic encounters tail vibration is performed not by the animal hesitating to attack, but by the victor whose opponent has vanished while in the sexual context it is shown not by the male, hesitating to approach a possibly aggressive female, but by the female, awaiting mounting.

The rattus situation could obviously provide the tarting point for ritualization of tail vibration into a copulation invitation signal from female to male but I am not aware of its yet having been found to have this significance in any species.

A second form of behaviour of some interest is the reared up paws-on posture. In $R$. rattus this is clearly a low intensity version of the boxing fight and it occurs most often during mating preliminaries when the female is repulsing the male. An almost exactly similar courtship procedure is seen in Cricetomys (Ewer 1967) and here also is very obviously derived from fighting. In $R$. rattus the common occurrence of a mouth to mouth contact in this posture has been mentioned and the possible relation of this to appeasement suggested. In both Onychomys (Ruffer 1966) and Thryonomys a mouth contact in the reared up position occurs as part of a somewhat complex courtship procedure. This is so similar to the $R$. rattus posture that it is impossible to believe that it is not in fact a homologous pattern.

Thryonomys has a highly specialized fighting technique that does not include boxing, so the courtship reared up mouth contact is presumably phylogenetically older than the aberrant fighting technique. The latter consists of a head-on pushing dual, nose against nose, reminiscent of artiodactyl frontal fighting. If one contestant relaxes pressure for an instant, the other may whip round and attempt to knock him off balance by a thwack of rump against rump and is back again in pushing position with extraordinary speed. It is not altogether easy to imagine how such a technique was ever evolved but one rat fight which $I$ saw suggests that it may be derived from broadside fighting.
This particular incident involved two young adult males. As a period of pre-mating male fighting came to a close, they were carrying on a low intensity broadside fight in a tree. They pushed against each other rather half heartedly and instead of doing so almost entirely with the hindquarters, they now and then brought their shoulders, necks and cheeks into contact and seemed almost to be making tentative moves towards mutual appeasement, before reverting to normal broadsiding. It would have needed only a slight further change of position to have converted this into a nose-pushing duel. It seems therefore that nose pushing may have evolved from broadsiding and that the rump thwack of Thryonomys is not a new addition to the pattern but a residium of the original broadside fighting technique.

In R. norvegicus, Barnett (1958) mentions lying down as a submissive action. Since amongst mammals this is probably the commonest of all forms of submission, there is nothing surprising about its occurrence in Rattus. In $R$. rattus, however, appeasement takes the very different form of mouth to mouth contact and it therefore becomes necessary to explain why there should be such a striking difference between two so closely related species. The obvious suggestion is that it relates to the arboreal habits of $R$. rattus. Lying down is not practicable on a vertical tree branch and is not even very safe on a horizontal one: mouth contact, on the other hand, is feasible even amongst the flimsiest branches. If this interpretation is correct and if the pattern is derived as suggested, from the wide-spread infantile saliva licking behaviour then it is quite probable that a similar form of appeasement will be found to exist in other arboreal species.

Salivia licking, or mouth suckling (Richardson 1943), is of some interest in its own right, since it appears to be a very common feature of rodent maternal behaviour. Whether it has any direct nutritional value remains to be investigated but it could also have secondary consequences of importance. Since the mother's mouth probably retains the smell of any food she has 
recently eaten, saliva licking may assist in the introduction of the young to solid food, which may be of importance in highly polyphagous species.

Another form of behaviour which may be regarded as an arboreal adaptation of $R$. rattus is scent marking by rubbing the ventral surface on the object to be marked, a method used by many arboreal species belonging to a number of different orders. Specialized glandular areas on the ventral surface, although not developed in $R$. rattus, are found in a number of other species of the genus (Rudd 1966), but nothing is known of their function.

Eibl-Eibesfeldt (1953) has described many of the ways in which the highly arboreal Rattus rattus differs from the burrowing $R$. norvegicus. The present study has added a few further details, including the behaviour patterns of appeasement and of scent marking and the clinging response of the young, which appear to represent arboreal adaptations of $R$. rattus. The rate of tail growth also shows characteristics interpretable in the same light. The main interest of the present study, however, is that it has shown that in a free living population there is a definite social structure, without which it is difficult to see how the group could maintain its cohesion. A high level of aggression is necessary for the exclusion of intruders but within the group, appeasement performed and accepted in relation to social status, is a major factor in preventing disruption. The territory which has to be defended is no larger than is required to provide the necessities of life but exploration beyond its bounds ensures that a wider area is sampled and exploitation of any new amenity is therefore possible. This exploration must also facilitate the dispersal which is normally regulated in such a way that the group does not outgrow its food supply. The factors that make Rattus rattus so successful as a human associate include not only its polyphagous habits, its ability to gnaw through obstacles and its climbing abilities but also the combination of a strong tendency to investigate anything new in the environment with an equally strong alarm response to any sudden noise or movement. The fact that the latter behaviour matured in the normal way in the hand reared young indicates that familiarity with man does not lead to waning of this highly protective behaviour. 


\section{SUMMARY}

A population of wild Rattus rattus living in the roofs of the laboratory buildings was studied by supplying food every evening and watching the behaviour of the animals at the feeding place. Some observations were also made on caged animals.

The rats were predominantly of the black rattus variety but white-bellied greys appeared now and then. In breeding tests the grey colour behaved as though determined by a single recessive gene.

The study covered two periods of approximately 9 months each, separated by an interval of 3 months during which a reduced quantity of food was provided and the rat population underwent a major decline. During the two periods of richer feeding the population first increased and then stabilized at a level where the animals remained in good condition and there was no starvation. In the first 9-month period, stabilization was achieved by emigration of young adults who colonized neighbouring buildings. Towards the end of the second period, stabilization was achieved by limitation of breeding.

The rats accepted a wide variety of foods, including meat, and a number of instances of predation were seen. Small vertebrates as well as insects were killed and eaten. Small pieces of food were usually eaten in situ but large bits were taken up to the nests in the roof. Such differential treatment in relation to size may be a factor of some importance in the evolution of hoarding.

The rats visiting the feeding place formed a unit with a definite social structure. A single dominant male and never more than one, was always present and in certain circumstances a linear male hierarchy was formed. There were usually two or three mutually tolerant top ranking females who were subordinate to the top male but dominant to all other members of the group. Within the group attacks were directed downwards in the social scale. An attacked subordinate either fled or appeased and serious fights therefore did not develop. The most essential component of the appeasement appeared to be a mouth to mouth contact, which may be derived from the infantile pattern of 'mouth suckling'. Appeasement permitted superior rats to maintain their status without the necessity of carrying attacks on subordinates to the point where actual hurt was inflicted.

A group territory round the feeding place was defended against interlopers. Both sexes took part in chasing out intruders but since males showed inhibition in attacking females, the exclusion of strange females was due principally to the activities of the home females. The point at which pursuit of an intruder stopped was regarded as the territorial boundary. This was also the limit beyond which a group member would not allow himself to be chased but it was not a prison wall. When agonistic tendencies were not aroused the animals no longer always turned back at the boundary and foraging beyond its limits allowed them to become familiar with an area larger than the territory.

Although intruders were normally driven out, it was occasionally possible for a particularly determined animal of either sex to force its way in and ultimately become a member of the group.

The patterns of behaviour seen are described, particularly those concerned with hostile encounters and with mating.

Scent marking with urine drip trails was not seen but adults of both sexes marked by rubbing the cheeks and ventral surface on branches.

The circumstances in which tooth gnashing was heard suggest that this behaviour is not a form of threat but a response to unfamiliar auditory or visual stimuli. There was some evidence that it functioned as an alarm signal within the group.

Pilo-erection and a gait or posture with the hind legs much extended ('stegosauring') are considered to function as threats. Pilo-erection 
occurred in situations where there was little to suggest conflict and is considered to represent a form of threat which has undergone emancipation.

Various forms of displacement and ambivalent behaviour were seen. Rapid vibration of the tail occurred in thwarting situations, either during mating or when a defeated opponent suddenly vanished. There was no evidence that it acted as a signal.

The common form of amicable behaviour was social grooming. Another amicable action was sitting together with the bodies in contact.

Animals reared in cages remained shy and wary and even hand reared young developed the usual alarm responses to movement and noises.

Females had their first litters at ages of 3 to 5 months. For first litters gestation periods were 21 to 22 days but in females that were simultaneously lactating they ranged from 23 to 29 days. Eight was the commonest litter number and ten the highest recorded.

At birth the tail is very much shorter than the body but has outstripped it by the time the youngster emerges from the nest. This was found to be the result of a period of extremely rapid tail growth immediately preceding emerg- ence. In Rattus norvegicus the peak in tail growth rate was found to be later and less striking. The difference is interpreted as related to the importance of the tail in climbing in the more arboreal $R$. rattus.

During the second week of life an edge response (retreat from a declivity) and a clinging response made their appearance: these have the function of preventing accidental falls from a nest situated above ground level.

Mouth suckling was seen only during a period of a few days towards the end of lactation.

Play developed within a few days of emergence from the nest: locomotor and fighting play were the common types. Older animals occasionally joined in play with the young.

In problem solving tests, first solutions were not insightful but once a solution had been found, the successful technique was at once adopted and subsequently perfected. There was no evidence of learning by imitation but the rats did learn from each other's behaviour that food could be obtained at a certain location and thus the solution of a problem by one rat accelerated its independent solution by others.

The reasons for the differences between the behaviour of the free living population and the caged animals studied by other authors are discussed. 


\section{REFERENCES}

Anon (1966). Country rats win gnawing stakes. $S$. Afr. J. Sci., 64, 224.

Barnett, S. A. (1958). An analysis of social behaviour in wild rats. Proc. zool. Soc., Lond., 130, 107-152.

Barnett, S. A. (1963). A Study in Behaviour. London: Methuen.

Barnett, S. A. \& Spencer, M. M. (1951). Feeding, social behaviour and inter-specific competition in wild rats. Behaviour, 3, 229-242.

Barnett, S. A., Bathard, A. H. \& Spencer, M. M. (1951). Rat populations and control in two English villages. Ann. appl. Biol., 38, 444-463.

Barnett, S. A., Evans, C. S. \& Stoddart, R. C. (1968), Influence of females on conflict among wild rats. J. Zool., 154, 391-396.

Barnett, S. A. \& Stoddart, R. C. (1969). Effects of breeding in captivity on conflict among wild rats. J. Mammal., 50, 321-325.

Blurton Jones, N. G. (1968). Observations and experiments on causation of threat displays of the great tit (Parus major). Anim. Behav. Monogr., 1, $75-160$.

Bruce, H. M. (1959). An exteroceptive block to pregnancy in the mouse. Nature, Lond., 184, 105.

Carlier, C. \& Noirot, E. (1965). Effects of previous experience on maternal retrieving by rats. Anim. Behav., 13, 423-426.

Chasen, N. F. (1933). On the forms of Rattus rattus occurring on the mainland of the Malay peninsula. Bull. Raffles Mus., 8, 5-24.

Clemens, L. G. (1969). Experimental analysis of sexual behaviour of the deer mouse Peromyscus maniculatus gambeli. Behaviour, 34, 267-285.

Dieterlen, F. (1963). Vergleichende Untersuchungen zur Ontogenese von Stachelmaus (Acomys) und Wanderratte (Rattus norvegicus). Beiträge zum Nesthocker-Nestfluchter-Problem bei Nagetiere. Z. Säugetierk, 28, 193-227.

Eibl-Eibesfeldt, I. (1953). Ethologische Unterscheide zwischen Haustratte und Wanderratte. Verh. dtsch. zool. Gesell., 1952, 169-180.

Ewer, R. F. (1966). Juvenile behaviour in the African ground squirrel, Xerus erythropus (E. Geoff.). $Z$. Tierpsychol., 23, 190-216.

Ewer, R. F. (1967). The behaviour of the African giant rat (Cricetomys gambianus Waterhouse), $Z$. Tierpsychol., 24, 6-79.

Ewer, R. F. (1969). Form and function in the grass cutter, Thryonomys swinderianus Temm. (Rodentia, Thryonomyidae), Ghana J. Sci, 9, 131-141.

Hinde, R. A. (1970). Animal Behaviour. McGraw-Hill.
Jirsik, J. (1955). Die Hausratte, Rattus rattus (Linne, 1758), wieder in der Tschechoslowakei. Säugetierk. Mitt., 3, 21-28.

Kühme, W. (1965). Die Ernährungsgemeinschaft der Hyänenhundes (Lycaon pictus lupinus Thomas 1902). Z. Tierpsychol., 22, 495-541.

Mainardi, D. \& Pasquali, A. (1966). Cultural transmission in the house mouse. Atti Soc. Ital. Scl. nat., $107,147-152$.

Mantalenakis, A. J. \& Ketchel, M. M. (1966). Frequency and extent of delayed implantation in lactating rats and mice. J. Reprod. Fert., 12, 391-394.

Morris, D. (1962). The behaviour of the green acouchi (Myoprocta pratti) with special reference to scatter hoarding. Proc. zool. Soc. Lond., 139, 701-732.

Myer, J. S. \& White, R. T. (1965). Aggressive motivation in the rat. Anim. Behav., 13, 430-433.

Myers, K. \& Poole, W. E. (1961). A study of the biology of the wild rabbit, Oryctolagus cuniculus (L.) in confined populations. II. The effects of season and population increase on behaviour. C.S.I.R.O. Wildl. Res., 6, 1-41.

Pippin, W. F. (1961). The distribution and movement of roof rats on Mona island, West Indies. $J$. Mammal., 42, 344-348.

Poole, T. (1967). Aspects of aggressive play in polecats. Z. Tierpsychol., 24, 351-369.

Richardson, W. B. (1943). Wood rats (Neotoma albigula): their growth and development. J. Mammal, $24,130-143$.

Ropartz, P. (1968). The relation between olfactory stimulation and aggressive behaviour in mice. Anim. Behav., 16, 97-100.

Rudd, R. L. (1966). The midventral gland in Malaysian murid rodents. J. Mammal., 47, 331-332.

Ruffer, D. G. (1966). Sexual bchaviour of the northern grasshopper mouse (Onychomys leucogaster). Anim. Behav., 13, 447-452.

Storer, T. I. \& Davis, D. E. (1953). Studies on rat reproduction in San Francisco. J. Mammal., 34, 365373.

Terman, R. C. (1969). Weights of selected organs of deer mice (Peromyscus maniculatus bairdii) from asymptotic laboratory populations. J. Maminal., 50, 311-320.

Watson, J. S. (1950). Some observations on the repro. duction of Rattus rattus L. Proc, zool. Soc. Lond., $120,1-12$.

Worth, C. B. (1950). Field and laboratory observations on roof rats, Rattus rattus (Linnaeus), in Florida, J. Mammal., 31, 293-304. 